\title{
Review Article \\ Preparation of Silver Nanoparticles and Their Industrial and Biomedical Applications: A Comprehensive Review
}

\author{
Adnan Haider and Inn-Kyu Kang \\ Department of Polymer Science and Engineering, Kyungpook National University, Daegu 702-701, Republic of Korea \\ Correspondence should be addressed to Inn-Kyu Kang; ikkang@knu.ac.kr
}

Received 1 July 2014; Accepted 16 September 2014

Academic Editor: Mangala P. Singh

Copyright (C) 2015 A. Haider and I.-K. Kang. This is an open access article distributed under the Creative Commons Attribution License, which permits unrestricted use, distribution, and reproduction in any medium, provided the original work is properly cited.

Silver nanoparticles (Ag-NPs) have diverted the attention of the scientific community and industrialist itself due to their wide range of applications in industry for the preparation of consumer products and highly accepted application in biomedical fields (especially their efficacy against microbes, anti-inflammatory effects, and wound healing ability). The governing factor for their potent efficacy against microbes is considered to be the various mechanisms enabling it to prevent microbial proliferation and their infections. Furthermore a number of new techniques have been developed to synthesize Ag-NPs with controlled size and geometry. In this review, various synthetic routes adapted for the preparation of the Ag-NPs, the mechanisms involved in its antimicrobial activity, its importance/application in commercial as well as biomedical fields, and possible application in future have been discussed in detail.

\section{Introduction}

Nanotechnology is booming by leaps and bounds due to the emergence of nanomaterials (particularly inorganic nanoparticles (NPs) and nanorods) with unique functions and size dependent physicochemical properties differing significantly from their bulk counterpart [1]. The potential of inorganic NPs has been explored worldwide in nanomedicine, drug delivery and biomedical devices, cosmetics, electronics, energy sector, and environmental protection [2-4]. Among inorganic NPs, silver nanoparticles (Ag-NPs or nanosilver), due to its novel chemical, physical, and biological properties as compared to their bulk form, have attracted the attention of researchers from various academic laboratories [5]. AgNPs have distinctive physical and chemical properties, for example, high thermal and electrical conductivity, surfaceenhanced Raman scattering, chemical stability, catalytic activity, and nonlinear optical behavior [6]. These properties take Ag-NPs to the top of the priority list, to be used in inks, in electronics, and for medical purpose [7].

Furthermore, Ag-NPs are widely known for its antimicrobial properties against microbes such as bacteria, fungi, and virus [8]. Due to their proven antimicrobial properties, AgNPs are widely used in the daily used commercial products, such as plastics, food packaging, soaps, pastes, food, and textiles, which has increased their market value to a great extent [9]. Its importance can be judged from the fact that AgNPs can be used in various form, such as colloidal (enamel, coating, and in paints), in liquid form (shampoo), or in solid form (blending Ag-NPs with a solid material such as polymer scaffolds) and even can be found suspended in materials like soap and nonwoven fabrics. Ag-NPs importance cannot be neglected even in textile industry, where Ag-NPs are used in the water filtration membranes. The idea behind the use of Ag-NPs in the water filtration membrane is based on the utilization of their proven antimicrobial properties and slow release rate of Ag-NPs from the membrane. The slow release rate prolongs capability of the membrane to be used as a protective barrier against various bacterial and other pathogenic microbes present in the water $[9,10]$.

Recently, the number of publications on the topic of AgNPs has increased rapidly and an increase of $93 \%$ in the number of published articles has been observed since 20012011. During this period, 247 articles were published in 2001, which in 2011 increased to 3603 articles. Most of these were published in the area of chemistry, materials science [10], physics, engineering, polymer science, spectroscopy, electrochemistry, molecular biochemistry, optics, and spectroscopy. 
A large number of consumer products having commercial value are being prepared parallel, banking on the literature published in the above mentioned period in the area of synthesis and applications [10].

Since vast literature on the Ag-NPs is present in the form of individual research articles that only focuses on the minor application part, we aimed to summarize it in the present review form so that the interested readers may find all recent information ranging from synthetic procedures to application in a single document. This paper aims to summarize the various methods adapted for the synthesis of Ag-NPs and the area in which these Ag-NPs were, are, and to be used so that it can be easy for common readers who wants to seek information related to these nanoparticles (see Figure 1). In this review paper every aspect of Ag-NPs, from synthesis to their application in the fields of environment, science, biology, molecular science, textiles industry, and last but not the least their role in medicinal fields, has been briefly explored. Besides, the future prospect of these nanoparticles in day to day life was also discussed.

\section{Synthetic Routes Adapted for the Synthesis of Ag-NPs}

Currently, variety of methods, such chemical, physical, photochemical, and biological, has been employed for the synthesis of Ag-NPs as depicted in Figure 2. Each method has its merits and demerits. The synthetic routes with commonly associated problems, that is, costs, stability, scalability, particle sizes, and size distribution for the Ag-NPs, have been described as follows.

2.1. Chemical Method. Among the existed reported methods, so far, chemical methods are preferred for the preparation of Ag-NPs due to the ease in synthesizing them in solution [11]. Many research groups and academia are using these methods to synthesize Ag-NPs in various sizes and shapes. For example, one research group synthesized monodisperse silver nanocubes by simply reducing $\mathrm{Ag}\left(\mathrm{NO}_{3}\right)$ with ethylene glycol in the presence of polyvinylpyrrolidone (PVP) polymer [12]; the process was called polyol process. In this process, it has been revealed that ethylene glycol works as both the solvent and the reducing agent. Furthermore, the size and shape of the nanocubes were dependent on the molar ratio of $\mathrm{Ag}\left(\mathrm{NO}_{3}\right)$ and PVP. Thus by controlling the experimental parameters, the geometry (size and shapes) of the Ag-NPs can be tailored. Round shaped Ag-NPs with a controlled size and monodispersity were synthesized by modifying the polyol method using precursor injection. In this method, particles with $20 \mathrm{~nm}$ or smaller size were prepared. The governing factors of the precursor injection method were precursor injection rate and in situ conditions (inside the reaction mixture). The injection precursor method proved to be effective in synthesizing particles with brilliant control on the size for the monodispersion [13]. In another reported method, monodispersed Ag-NPs were synthesized using $\mathrm{Ag}\left(\mathrm{NO}_{3}\right)$, oleylamine, and liquid paraffin. Oleylamineparaffin system was used for controlling high temperature which paid pivotal role in determining the particle size of the synthesized Ag-NPs. Liquid paraffin was used to sustained high temperature and secondly helped in avoiding the use of solvents that would hamper the whole synthetic process [14]. Normally, the synthesis of Ag-NPs by chemical method banks on three factors (stages): (a) Ag precursor, (b) reducing agents, and (c) stabilizing agent. Furthermore, the synthesis and geometry of Ag-NPs rely on the nucleation and subsequent stacking of the Ag nuclei. Uniform size and monodispersity can be achieved by controlling the nucleation stage and stacking of nuclei in which intern depends on experimental parameters such as precursor, $\mathrm{pH}$, temperature, and reducing agents. More recently, Mukherji and Agnihotri synthesized Ag-NPs using $\mathrm{Ag}\left(\mathrm{NO}_{3}\right)$ as precursor and sodium borohydride and trisodium citrate as reducing and stabilizing agent. The size of the Ag-NPs was controlled by optimizing the experimental parameters and was in the range of $5 \mathrm{~nm}$ to $100 \mathrm{~nm}$. Furthermore, they elucidated the effect of size and dose dependent property of the synthesized Ag-NPs. From the analysis of the obtained results, they revealed that AgNPs with small size show excellent antibacterial activity as compared to its other counterparts [15].

The formation of colloidal solutions from the reduction of silver salts involves two stages of nucleation and subsequent growth. The authors also revealed that the size and the shape of synthesized Ag-NPs are strongly dependent on aforementioned stages. Furthermore, for the synthesis of monodispersed Ag-NPs with uniform size and monodispersity, simultaneous formation of nuclei is required. By doing so all of the nuclei are likely to have the same or similar size, which will be followed by subsequent growth. The initial nucleation and the subsequent growth of nuclei can be controlled by adjusting the reaction parameters such as reaction temperature, $\mathrm{pH}$, precursors, reduction agents (i.e., $\mathrm{NaBH} 4$, ethylene glycol, and glucose), and stabilizing agents (i.e., PVA, PVP, and sodium oleate) $[16,17]$.

2.2. Physical Method. Along with the chemical methods used, various alternative techniques were also adopted by researchers for the synthesis of Ag-NPs. Usually in those techniques, evaporation and condensation processes are implemented for the synthesis of Ag-NPs. Similar to chemical method, these methods have their own merits and demerits. One of the most common drawbacks of these methods is the higher energy requirement and time consuming. Therefore, researchers have reported numerous alternative physical methods for the synthesis of Ag-NPs instead of implementing conventional condensation and evaporation method. These methods not only reduced the preparation time but also are energy friendly. For example thermal-decomposition method was implemented for the synthesis of Ag-NPs in solid form. In such method, complexation reaction between Ag and oleate at elevated temperature was carried out for the synthesis of Ag-NPs with particle size less than $10 \mathrm{~nm}$ [22]. In another work Jung et al. reported that Ag-NPs with uniform size and monodispersion can be prepared using ceramic heating system, for supplying continuous heat without any fluctuation [23]. The heating system was used in order to evaporate the precursor used in the preparation of Ag-NPs. Tien et al. used arc discharge technique for the synthesis 


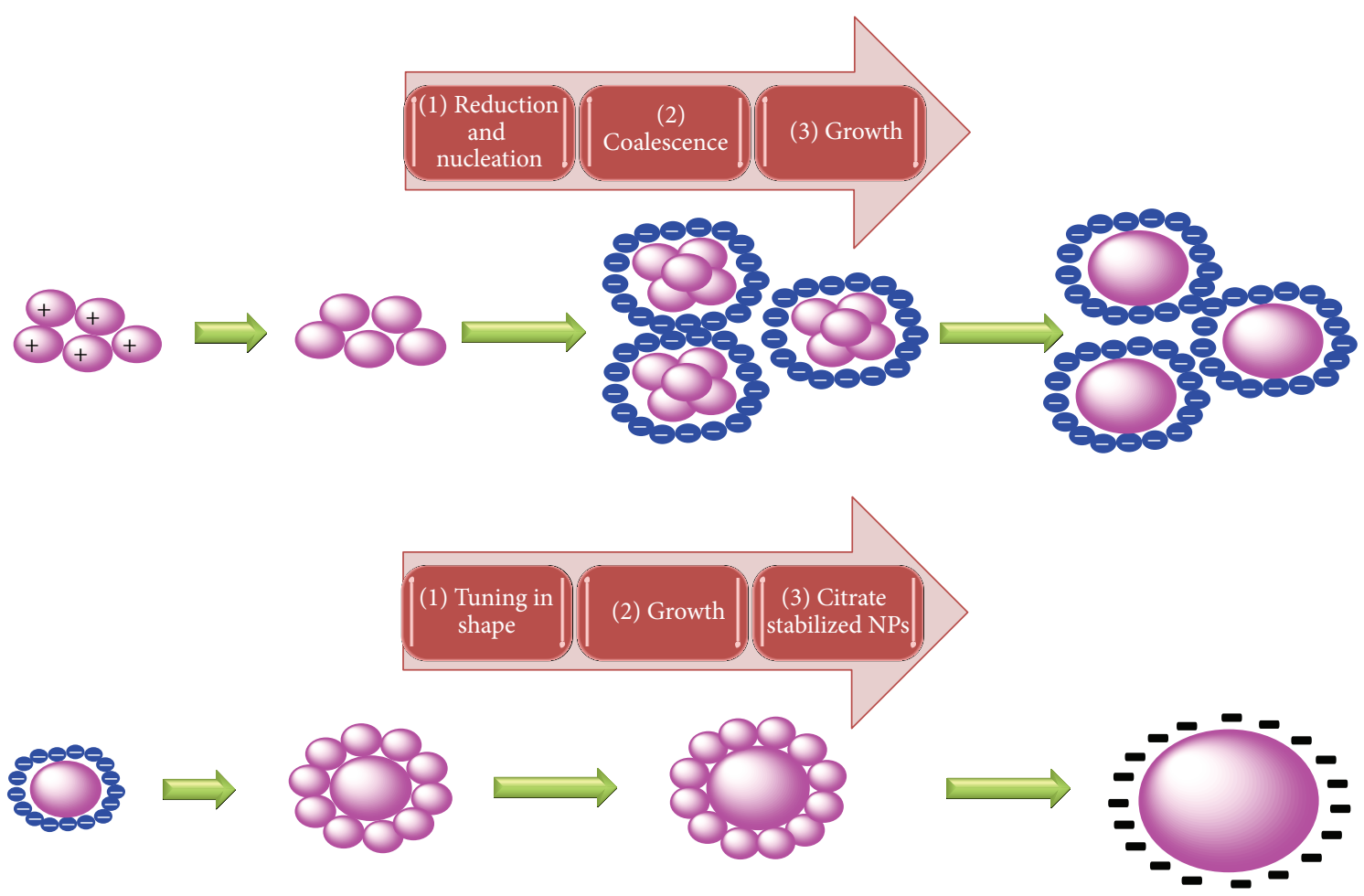

FIGURE 1: Schematic representation of size controlled synthesis of Ag-NPs using coreduction method.

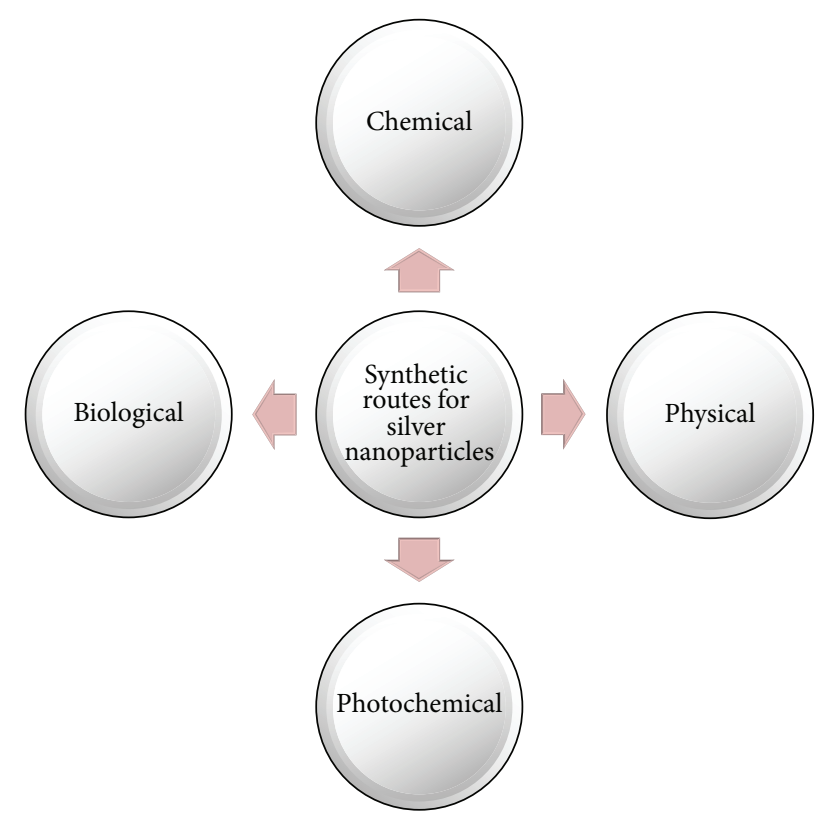

FIGURE 2: Various synthetic routes adopted for the synthesis of AgNPs with uniform geometry.

of Ag-NPs in DI water, avoiding the use of surfactant. The authors used electrodes made of silver that were dipped in $\mathrm{DI} \mathrm{H}_{2} \mathrm{O}$. The results reported by Tien et al. using arch discharge technique showed that the size of the synthesized Ag-NPs was less than $10 \mathrm{~nm}$ [24]. Later on Kuo et al. used electric discharge machining system for the synthesis of Ag-NPs by optimizing the experimental parameters. The authors performed experiment for elucidating the effect of the process parameters on the characteristic of Ag-NPs [10, $25,26]$. Recently researchers reported a unique technique for the physical synthesis of Ag-NPs with uniform geometry and particle size less than $5 \mathrm{~nm}$ along with improved dispersion. The technique was proposed to be an alternative for chemical techniques with the added advantage of saving time. AgNPs were also prepared by sputtering of metal into reaction mixture, that is, physical deposition of Ag into glycerol. Physical techniques used for the preparation of Ag-NPs having uniform particle size and shape are mostly govern by the thermal, ac power, and arc discharge. By adopting these aforementioned techniques, bulk amount of Ag-NPs can be synthesized in a single process which will save time and the purity of the Ag-NPs particles will not be compromised. However, the cost is considered to be the main hurdle in adopting such method as it needs expensive equipment [10].

2.3. Photochemical Synthesis. In the photochemical techniques mainly two different methodologies are implemented for the synthesis of Ag-NPs: (a) photophysical and (b) photochemical techniques. In the photochemical techniques Ag-NPs are synthesized by photoreduction of precursor or Ag ions using photochemically activated intermediates such as radical [27]. In one of the method Ag-NPs were synthesized using UV radiation and aqueous solution containing Triton $\mathrm{x}-100$ which acts as stabilizing agent. The surfactant used in the study helped in maintaining the stability, monodispersion, and uniform size of the synthesized Ag-NPs [28]. In another reported method, Ag-NPs were synthesized 
from aqueous solution of alkali containing $\mathrm{AgNO}_{3}$ and carboxymethylated chitosan (CMCTS) using UV radiation. CMCTS was used as reducing agent with the added advantage of enhancing the stability of the synthesized Ag-NPs. The diameter of the synthesized Ag-NPs was less than $10 \mathrm{~nm}$. The stability of synthesized Ag-NPs was more than 6 months in the alkali/CMCTS alkali solution [29]. Balan et al. reported an improved photochemical method for the synthesis of Ag-NPs which involved the direct photoreduction of $\mathrm{AgNO}_{3}$ with the help of laser source capable of emitting radiation in the range of near infrared (IR) region. They used dyes as photoactive agents [30]. The merits of photochemical techniques for the preparation of Ag-NPs were (a) high purity of the synthesized Ag-NPs and easy processing; (b) Ag-NPs were prepared by UV-radiation with the help of reducing agents; (c) wide range of reaction medium can be used that can be glass, polymer, micelles, emulsion, and so forth [31].

2.4. Biological Synthesis. Using conventional methods for the synthesis of Ag-NPs requires (a) Ag precursors, (b) reducing agent, and (c) stabilizer/capping agent (PVP) (for avoiding agglomeration of the newly synthesized Ag-NPs). However in biological techniques, biomolecules replaced the conventional reducing and stabilizing agents. In biological methods Ag-NPs are synthesized using plants (such as algae, yeast, fungi, and bacteria) as reducing and stabilizing agents [32]. Shewanella oneidensis (a metal reducing agent) was used for the biosynthesis of Ag-NPs using $\mathrm{Ag}\left(\mathrm{NO}_{3}\right)$ solution as precursor. The synthesized Ag-NPs size was less than $15 \mathrm{~nm}$, with uniform dispersion, spherical shape, enhanced stability, and large surface area. Such methods used for the synthesis of Ag-NPs are highly economical and reproducible and consume lesser energy contrary to the conventional methods [33]. In another study, Trichoderma viride fungus was used for the biosynthesis of Ag-NPs from $\mathrm{Ag}\left(\mathrm{NO}_{3}\right)$ precursor [34]. The geometry of the biosynthesized Ag-NPs was highly variable with particles size less than $50 \mathrm{~nm}$. Furthermore, stable Ag-NPs with size less than $20 \mathrm{~nm}$ were synthesized by using airborne bacteria (Bacillus sp.) using $\operatorname{Ag}\left(\mathrm{NO}_{3}\right)$ as the precursor. The biosynthesized Ag-NPs were collected from the periplasmic region (a space between outer and inner membrane) of the bacterial cell. Moreover, spherical AgNPs synthesis was reported by the reduction of $\operatorname{Ag}\left(\mathrm{NO}_{3}\right)$ phyllanthin extract at room temperature. The size and shape of the Ag-NPs were governed by concentration of phyllanthin extract [35, 36]. In another study published by Venkata Subbaiah and Savithramma, the authors revealed that AgNPs can also be synthesized from Cadaba Fruticosa leaves using $\mathrm{Ag}\left(\mathrm{NO}_{3}\right)$ as precursor. The biological synthesized nanoparticles were very potent against microbes [37].

\section{Effect of Shape, Size, and Chemical Forms of Ag-NPs}

Many scientists have reported on the particle size dependent activity of Ag-NPs, although it is not a rule [38, 39]. Powers et al. presented size dependent properties of PVP-capped AgNPs. In others studies, researchers suggested that the smaller is the size the more is the cytotoxicity. This could be attributed to the fact that small sized Ag-NPs have easier uptake, easy dissolution, and smooth release of Ag-NPs ions along with increased surface area [40]. Some of the studies emphasized on the mass based property of Ag-NPs without taking particle size and surface area into consideration. It has also been proposed that surface modification of Ag-NPs enhances the dissolution and stability of these nanoparticles (for longer time) $[38,39]$. As biomolecules, coating and capping agents can affect the size, shape, and interfacial properties of the Ag-NPs.

Therefore researchers have highlighted the fact that size shape and surface area are the governing factor in determining the extent of cytotoxicity of Ag-NPs. For this reason numerous techniques such as dynamic light scattering (DLS), transmission electron microscope (TEM; see Figure 3), and centrifugation have been employed to facilitate accurate measuring of size and dispersion of these nanoparticles [41, 42].

\section{Application of Ag-NPs}

Ag-NPs have been in use for more than 150 years and are recognized as antimicrobial agent in United States (USA) since 1954 [43]. There are many assumptions about the use of silver by the ancient Egyptian and Romans. The most stable oxidation state of $\mathrm{Ag}$ is +0 and +1 although it can exist in other oxidation states as well and can form various complexes. $\mathrm{Ag}\left(\mathrm{NO}_{3}\right)$ is considered as a precursor for the synthesis of Ag-NPS. The size and geometry of Ag-NPs are dependent on the synthetic route adopted for its synthesis; however it can be found in spherical, rod, and triangular shape, or coated with polymer, biomolecules, and sugars. Ag-NPs has numerous chemical, physical and biological functions which are explained point by point.

4.1. Textiles. Fabrication of functionalized fabrics with AgNPs has a fair share in the functionalized fabricated materials [44]. Blaser et al. proposed an exposure model in which fabrics functionalized with Ag-NPs and polyethene bags are considered to be the prime governing factors for presence of silver in the atmosphere [45]. Garments such as socks, Tshirts, sports-wear are functionalized with Ag-NPs, but the most advantageous use of Ag-NPs is considered to be in medical field because of the high risks of contamination associated with surgical suits [46]. Freeman et al. reported the effect of Ag-NPs functionalized fabrics on bacterial contamination.

Freeman et al. reported the effect of Ag-NPs functionalized fabrics on bacterial contamination. Which stated that Ag-NPs functionalized fabricated fabric has a prime role in retarding the bacterial colonial growth $[10,32,47-$ 49]. Various techniques are adopted for the fabrication of fabric functionalized with Ag-NPs; for example, the most famous and talked about techniques used for the fabrication of silver containing fabrics are by blending Ag-NPs with the fabricated material so that the Ag-NPs are embedded inside the functionalized fabrics or secondly by the surface immobilization of fabrics (to be functionalized) with Ag-NPs. However, along with the merits such fabrics do have demerits such as release of Ag ions during washing which is considered to be the prime concern regarding the durability of such Ag-NPs functionalized materials [47, 48, 50]. Furthermore 

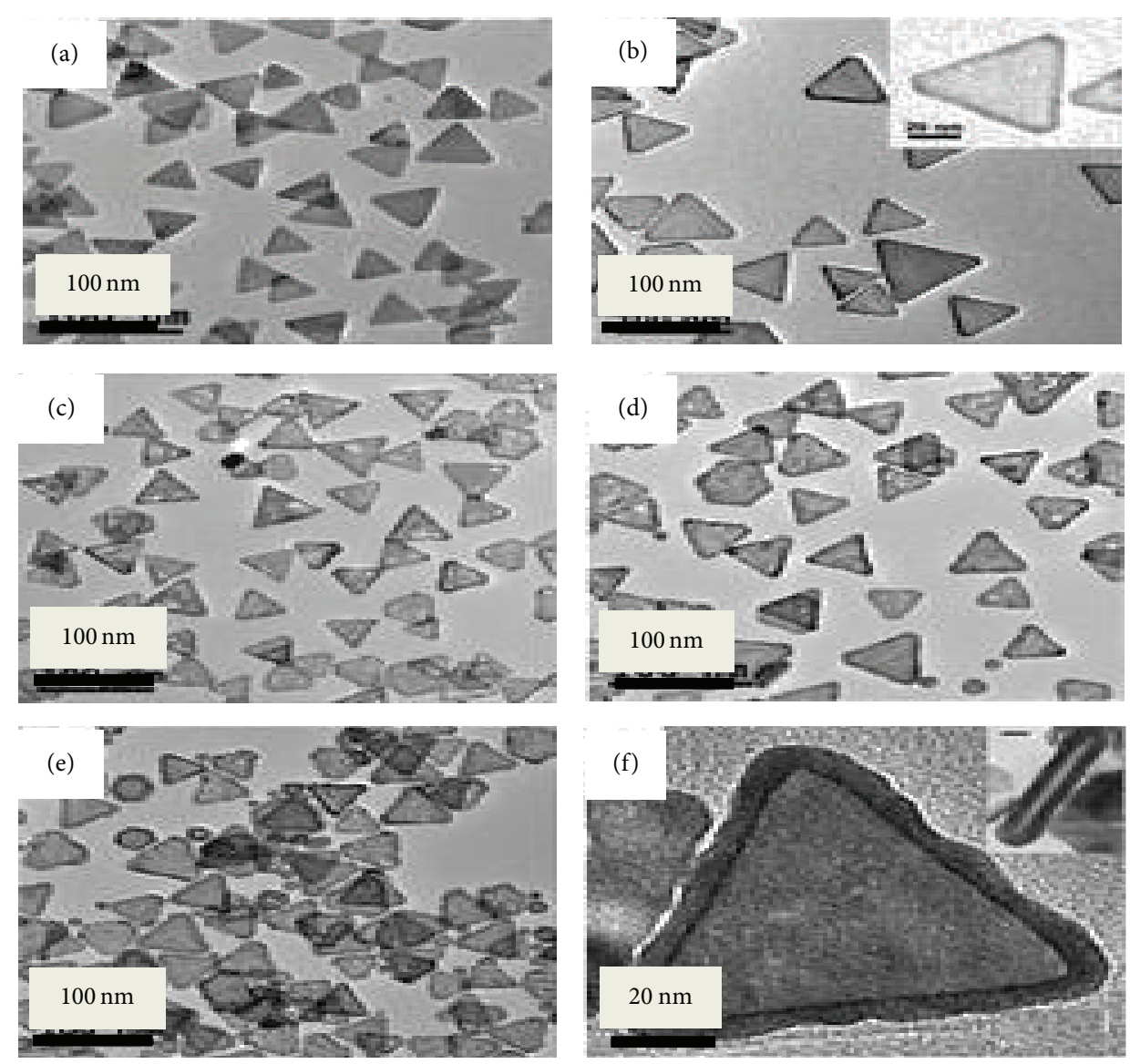

FIGURE 3: TEM images of (a) initial silver nanoprisms; (b) samples at $45 \mathrm{~min}$ with gold deposition on the prism edges; (c) samples from stage 2 with some small pinholes; (d) samples with partially refilled pinholes after 120 min (stage 3); (e) samples at 200 min with full gold shells (stage 4); (f) a typical final gold-coated nanoprism (the inset is the cross-sectional view with a scale bar of $10 \mathrm{~nm}$ ). Reproduce from Shahjamali et al. with permission from wily publisher [18].

composite fabrics containing Ag-NPs present in the sheath part revealed promising antibacterial activity on the contrary to the fabrics containing Ag-NPs in the core part [51].

4.2. Food Packaging. As already discussed the merits of AgNPs functionalized fabrics likewise Ag-NPs have also made its mark in the food packaging industry and are known to be one of the important components in the packaging materials used for preservation of food for longer duration. For example, materials whose surfaces are coated with Ag-NPs can be useful in preventing the preserved food from contamination (preventing contamination caused by microbes) due to slow release of Ag-NPs from the coated surface along with preventing growth of the microbes on the surface of the packaging material (effect of Ag-NPs against microbes will be discussed in detail in the later part of this review). Researchers working in the field of food preservation have reported sonochemical coating, a simple and versatile technique used for preparation of coating materials from the colloidal solution containing Ag-NPs using ultrasonication [52]. The coating proved to be effective against various strains of bacteria (gram-negative E. coli and gram-positive S. aureus bacteria). The method proved to be a step forward towards the synthesis of materials with the help of which food can be preserved for longer duration. Cushen reported that Ag-NPs have significance in research relating food preservation and packaging industry. However only limited forms of Ag-NPs are allowed by the EFSA (European Food Safety Authority) which can be used in food packaging and preservation [53].

4.3. Plastic Coatings. The importance of Ag-NPs in preparation of medical devices can be judged from the fact that a wide range of medical devices are prepared from it due to its potency against various strained of bacteria (gram positive and gram negative). Catheters are usually prepared from materials that contain Ag-NPs in order to avoid infection and contamination. These catheters are useful in sustain and targeted release of $\mathrm{Ag}$ ions from the Ag-NPs which ultimately prevents microbial activity. Roe et al. synthesized catheters coated with Ag-NPs. From the obtained results the authors concluded that along with inhibiting the formation of biofilm these catheters were nontoxic and showed sustained release of Ag-NPs [54]. In hospitals products made from Ag-NPs are used as protecting materials against microbial activity; usually these protecting materials are made up of plastic containing Ag-NPs on the surface or inside the plastic 
materials. Furthermore materials coated with Ag-NPs can be used in preventing microbial activity in water; for example, Doolette et al. revealed that Ag-NPs coating can be effective in preventing the microbial activity in water $[55,56]$.

4.4. Nanoprism Preparation. Recently scientist has diverted their attentions towards the synthesis and optical activity of Ag-NPs nanoprisms. Ag-NPs having unique optical activity which results in surface-plasmon resonance (SPR) peaks at relatively long wavelengths. Focusing on silver, various physical and chemical processes have been adopted for the fabrication of nanoprism. One of the processes for making Ag-NPs nanoprism is lithographic technique (nanosphere lithography (NSL)). In this technique Ag-NPs are synthesized and are kept on solid substrates that are capable of producing nanoprisms with control over its geometry. Although these lithography techniques are considered to be an alternative to solution-phase technique, chemical techniques are more versatile compared to physical technique. So far two main chemical techniques are identified as stand-out among all of the other techniques: (a) chemical reduction method and photoinduced aggregation of Ag-NPs [57]. The latter became very popular in recent time. Callegari et al. reported that filters during illumination have direct influence on the morphology of the nanoprism prepared from Ag-NPs. In a detailed mechanistic study, Callegari et al. [58] proposed that the whole process is controlled by charge distribution on the Ag-NPs during photoinduced illumination using a laser beam of specified wavelength. In one of the other studies reported researcher in that group proposed that modifying the photoinduced technique using low-intensity lightemitting diodes (LEDs) with different emission wavelengths in combination with various color filters for illumination allows the preparation of Ag-NPs nanoprism having high aspect ratio, so that the in-plane dipole plasmon resonance is shifted to wavelengths above $\mu \mathrm{m}$. Furthermore they also suggested mechanism for justifying their reported work [57, 59]. Silver nanoparticles (Ag-NPs) having large absorption coefficients around $1.55 \mu \mathrm{m}$ could be used, for coating communication fibers, so that it enables reducing the loss of communication and signal contamination. Moreover it can be used in other fields such as biotechnology, as targeted localized heating system using low energy irradiation [60]. Shahjamali et al. synthesized surfactant free gold-coated Ag-NPs nanoprism. The gold coating provided stability to Ag-NPs nanoprism against etching, the nanoprism had clean surfaces, and the purity endows those gold coated Ag-NPs nanoprism to be used in fields of biosensing and bioimaging [18].

\section{Role of Ag-NPs in Environment}

Silver nanoparticles (Ag-NPs) are world widely famous for their versatility which they exhibit in terms of applications such as electrical, thermal, and antimicrobial properties. In the past people used Ag for ornamental, medicinal, crockery, clothing, building materials, and coins making and as disinfectant. Reports suggested that Ag-NPs have no side effect on the body and act as antimicrobial agent when used with proper care (proper amount) [61-64]. Previously silver salts were used for the treatment of mental disorders, drug addiction, and several infectious diseases caused by pathogens $[64,65]$.

5.1. Water. Ag-NPs are widely known for its potent properties against pathogens, preventing infections and antimicrobial activity. With durability and their antimicrobial activity, AgNPs are considered to be a useful tool against infectious diseases caused by the microbes present in the environment. Therefore its high potency against various infectious microbes can help in avoiding and curing microbial infections. Recently researchers reported disinfectant ability of colloidal Ag-NPs for the treatment of gastrointestinal bacterial infections. One of the other reported studies proposed that core shell magnet nanoparticles comprised of Ag-NPs are effective disinfectant in water purification system [66]. These core shell magnetic nanoparticles exhibited excellent antimicrobial and antipathogenic properties [67]. Most importantly these core/shell magnets can be successfully recovered from the system with the help of external magnet field. Thus the environment can be protected from the hazardous threat caused by pathogens and from the side effect of core/shell magnetic nanoparticles and can be reused [68]. Furthermore cores/shell magnetic nanoparticle can be used in biomedical application for targeted drug delivery, in disposable wipes, for cleansing hands, in sprays, and in maintaining personal hygiene. In a published article, the authors revealed that the use of filter containing Ag-NPs can ensure 100\% bacterial inhibition compared to their counterpart [69].

5.2. Air. There is concern over the impact of Ag-NPs to mankind and animals, as several reported studies revealed that Ag-NPs have great penetration ability in different environment. Humans and animals are exposed to these AgNPs via breathing, ingestion, through skin, and so forth. Therefore concerns arise regarding the impact of Ag-NPs to human and animals health. Due to the small size these nanoparticles can easily penetrate through different organs and ultimately reach the cytoplasm of the cell. For the confirmation of the cytotoxicity of Ag-NPs through breathing Ji et al. conducted experiments on Sprague-Dawley rats for 4 weeks. With different exposure time to the Ag-NPs the rats did not exhibit any abnormal behavior and no change in-terms of weight was observed because of inhalation of Ag-NPs. Furthermore no remarkable changes in the blood biochemical and haemotology were observed [70]. However some scientists have reported that lungs are the primary target which are affected by prolong exposure to Ag-NPs [71]. In one of the other articles published by Lee et al. they have reported that Ag-NPs exposure modulated the expression of several genes associated with motor neuron disorders, neural disease, and immunity system of the body, suggesting the potential toxicity of the Ag-NPs to the neural and immune system of the body [72]. Minor pulmonary cytotoxicity (inflammation) in mice was observed after exposing them for longer duration to Ag-NPs [73]. Kim et al. investigate the oral toxicity of Ag-NPs for 4 weeks in Sprague-Dawley rats. It was observed from the experiments that changes in weight of male and female were observed relative to the dose of 
Ag-NPs; however it has caused some alkaline and cholesterol changes which were assumed to be dose dependent [74]. Furthermore it was proposed that Ag-NPs do not cause any genetic changes in rats. Some scientists showed their concern while reporting the studies on toxicology of Ag-NPs to organism via skin [75]. Generally very limited research has been done on the issue highlighting the effect of Ag-NPs on the mankind and wild animals; further studies in this field are the need of the day; however Ahamed et al. have summarized the studies relating the issue in his review entitling the study of the impact of Ag-NPs on the environment [8] in which the authors have given detailed information relating various disorder caused by the Ag-NPs such as reproductive disorder and morphological deformation.

5.3. Release of Ag-NPS from Functionalized Materials. Consumer product comprised of any form of silver (Ag) is the main cause of silver release into the environment. Several articles have been published concerning the release of silver from wide range of materials that use silver nanoparticles (Ag-NPs) in their products such as functionalized fabrics paints $[46,76]$. Usually inductively coupled plasma (ICP), energy dispersive spectroscopy (EDS), and transmission electron microscopy (TEM) are used for the detection of released silver from the materials to be investigated. In a report published by Lorenz et al., the authors hinted that with the growth of nanoindustry nearly all products contain nanoparticles especially sprays [76]. They used four different kinds of sprays for their experiments and confirmed the presence of nanoparticles. In one of the studies conducted by Benn and Westerhoff they reported that manufacturing techniques play a vital role in the release of silver (Ag) from the fabrics functionalized with Ag-NPs. They performed their experiment on socks that were made using different manufacturing techniques. The results obtained confirmed the presence of Ag-NPs in both the wash water and the socks. The presence of released silver (Ag) was confirmed in colloidal and ionic form and was considered to be an important factor in the release of Ag into the environment [46]. In a published article the authors conducted experiments for the assessment of release of Ag from the fabrics functionalized Ag-NPs. The authors revealed that the most important factor for Ag release from the AgNPs functionalized fabrics is the processes used for their incorporation into the fabrics during fabrication [50].

\section{Mechanism of Action of Ag-NPs against Microbes}

Silver (Ag) and especially silver nanoparticles (Ag-NPs) antimicrobial activity, irrespective of the strains of bacteria whether they are antibiotically resistant or not, is famous around the globe in scientific community [77]. The confirmed mechanism is yet to be discovered but can be related to the mechanism of silver (Ag) ions action on bacteria strains such as trypanosomes and yeasts, where accumulation of AgNPs occurs from the aqueous solution that ultimately causes saturation of enzymes and protein in the cell $[77,78]$. In a published report the authors proposed the mechanism which states that the changes caused by the Ag-NPs in the cell wall and nuclear along with DNA and RNA are the main cause of retarding the bacterial cell growth. Meanwhile Li et al. proposed three possible mechanisms that can cause bacterial cells death using Ag-NPs particle [48].

(1) The first proposed mechanism states that the bacterial cell growth and proliferation are inhibited by the adhesion of Ag-NPs onto the cell wall (due to the fine particles size) of the bacteria thus causing changes in the cell wall in which intern is unable to protect the internal part of the cell [79].

(2) In the second proposed mechanism the authors stated the penetration of the Ag-NPs into the bacterial cell causing changes in the DNA retarding its normal function thus ultimately causing its death. Silver nanoparticles penetrate through bacterial cell wall, resulting in DNA damage.

(3) In the third proposed mechanism they stated that when Ag+ ions interact with the proteins containing sulphur present in the cell wall of the bacteria this ultimately leads to the malfunctioning of the bacterial cell wall. This process is assumed to be the main mechanism in explaining the antibacterial activity $[48,79-82]$. The various antimicrobial mechanisms have been depicted in Figure 4.

\section{Ag-NPs Role in Medicine}

7.1. Antibacterial Properties. The Ag-NPs are famous for its potent antibacterial activity against various strains of bacteria including highly pathogenic bacteria species (gram positive and gram negative bacteria) [83]. Sondi and Salopeck-Sondi investigated the antibacterial activities of Ag-NPs against E. coli on Luria-Bertani agar plates. The E. coli bacterial strains were used as representative species for gram negative bacteria. After the analysis of the obtained results the authors reported that the antibacterial activity of Ag-NPs against E. coli was dose dependent (concentration). At optimized experimental parameters, they found out that Ag-NPs were adhered to the cell wall of the gram negative bacteria ( $E$. coli) that caused the destruction of the bacterial cell [84]. In another reported study scientists conducted experiments on the size related properties of the Ag-NPs on different species of gram negative bacterial strains [85]. The results obtained from their study suggested that size of Ag-NPs is an important factor in preventing the bacterial cells from their normal functions. Furthermore they also reported that smaller particle can easily adhere to the cell wall of the bacterial cells thus hampering their normal behavior such as permeability and respiration along with the release of the $\mathrm{Ag}$ ions from the Ag-NPs particle. Furthermore in an another published study, researchers conducted experiments for elucidating the dose dependent properties of Ag-NPs on gram negative and gram positive bacteria; the authors reported that gram negative bacteria $(E$. coli) can be inhibited at relatively low concentration as compared to the gram positive bacteria (S. aureus) (see Figure 5). Shrivastava et al. revealed that the antibacterial activity of the Ag-NPs is both size and dose dependent; furthermore they also proposed 


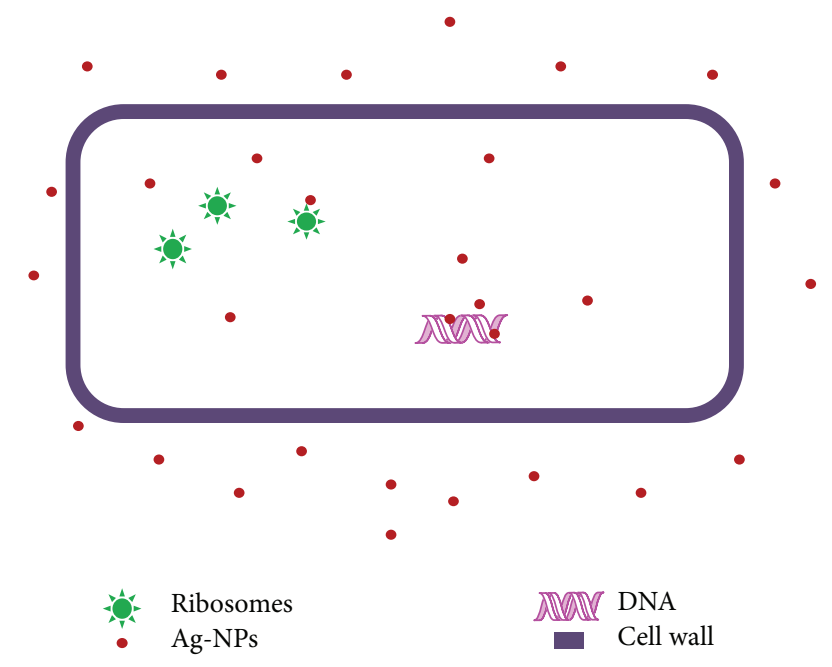

FIGURE 4: Schematic of antibacterial activity of Ag-NPs. Ag-NPs get adhered to the cell wall of bacterial cell through sulphur present in the protein comprising the bacterial cell wall, ultimately causing bacterial cell death. Ag-NPs also hamper protein synthesis along with directly causing damage to the interior of the bacterial cell by directly penetrating the cell wall and cell membrane.

the possible mechanism for the antibacterial activity of AgNPs, which states that the antibacterial activity of the AgNPs is governed by the adhesion and penetration pattern of the Ag-NPs into the cell wall of the bacterial cell, ultimately resulting in abnormal function [86]. In a study published by Pal et al., the authors revealed that the antibacterial activity of the Ag-NPs is structure (morphology) dependent [87].

7.2. Antifungal. Fungi are considered to play a vital role in causing fungal infections, especially in hospitals [88]. Along with the antibacterial activities of the Ag-NPs numerous studies had been reported on the antifungal activities of AgNPs, which reveals that Ag-NPs could be used as effective antifungal agent because Ag-NPs exhibit excellent antifungal properties against various species of fungi. In a report published by Kim et al. they tested the antifungal activities of the Ag-NPs against different fungal strains such as Trichophyton mentagrophytes (T. mentagrophytes) and Candida albanicans (C. albanicans) fungi and revealed that Ag-NPs exhibited good antifungal activity. Furthermore they also proposed the possible mechanism for the antifungal activity of AgNPs, which states that Ag-NPs cause abnormalities in the cell wall of the fungi which results in the abnormal functions (retarding the normal budding process) of the fungal cells (C. albanicans) $[10,88,89]$. In another published paper researchers found out that catheters coated with Ag-NPs can result in complete inhibition of fungi (C. albicans). Recently, scientist reported the antifungal activities of Ag-NPs synthesized by tollens method. From the obtained results they revealed that the yeast cells proliferation can be inhibited with the help of Ag-NPs along without causing any harm to human fibroblastic cells. Another reported work states that Ag-NPs have exhibited antifungal activities against different strains of fungi such as C. albicans and C. glabrata Trichophyton rubrum (T. rubrum) but the activity is dose dependent [90]. In short due to the reported literature available on the antifungal activity of Ag-NPs, it can be concluded that Ag-NPs can be used as antifungal agent against various strains (species) of fungi and can be helpful in overcoming various fungal infections caused by fungi.

7.3. Antiviral Agent. Recently, the increase in infectious diseases caused by virus such as SARS-Cov, influenza A/H5N1, influenza A/H1N1, Dengue virus, HIV, HBV, and new encephalitis viruses, is of prime concern. These infections can create havoc in no time because of the rapid proliferation (glimpses of destruction caused by these viral infections have been observed in some of the countries and the most dangerous of these viral infections were bird flu, swine flu, and dengue), ultimately resulting in causing severe damage to health and wealth of humans beings [91]. Ag-NPs are famous for their antimicrobial activities; therefore researchers have diverted their attention and started evaluating the importance of Ag-NPs in controlling infectious diseases caused by pathogens and viruses. However the number of reported works using Ag-NPs for controlling viral infections is very low but still it can pave the way for other researchers to show their interest in dealing against viral infections using nanoparticle specifically Ag-NPs. Elechiguerra et al. published their study conducted for assessing the effect of Ag-NPs on the HIV-1 virus. The authors concluded and revealed that the interaction between Ag-NPs and virus is size dependent (small sized nanoparticles are more effective against these viruses) [92]. They further enlightened the idea that Ag-NPs get adhered to the sulphur present in the gp120 glycoprotein knobs that results in hampering the normal activities of the virus therefore hindered the normal functions of the virus. This mechanism was second by another group of researchers when they published their report after assessing the role of Ag-NPs on HIV virus [92]. According to their published article they proposed that Ag-NPs were effective against HIV virus having the capability to bind to the sulphur present at gp120 glycoprotein knobs thus ultimately retarding their normal functions and binding to the hosts $[10,92]$.

Furthermore in a published article the authors reported that Ag-NPs play a vital role in inhibiting the synthesis of HBV RNA and extracellular virions in vitro (hepatitis B virus using HepAD38 cell line) $[10,93]$. Sun et al. published their research work in which they conducted experiments on the PVP (polyvinylpyrrolidone) coated Ag-NPs in combination with protein for controlling the infection caused in HEp-2 cell by syncytial virus (RSV) [94]. They revealed that PVP coated Ag-NPs are effective in preventing the RSV virus infection. Furthermore they proposed the possible mechanism which stated that the PVP coated Ag-NPs bind to the G proteins present on the surface of viral cell thus suppressing the adhesion of the RSV virus cells to the host cells. Other researchers conducted experiment on Ag-NPs (having different size and geometry) and reported that Ag-NPs are very effective in inhibiting the normal functions of monkey virus [95]. De Gusseme et al. reported the usefulness of bio-AgNPs (biogenic Ag-NPs), and they concluded that both AgNPs and ionic Ag+ play very important role in controlling 

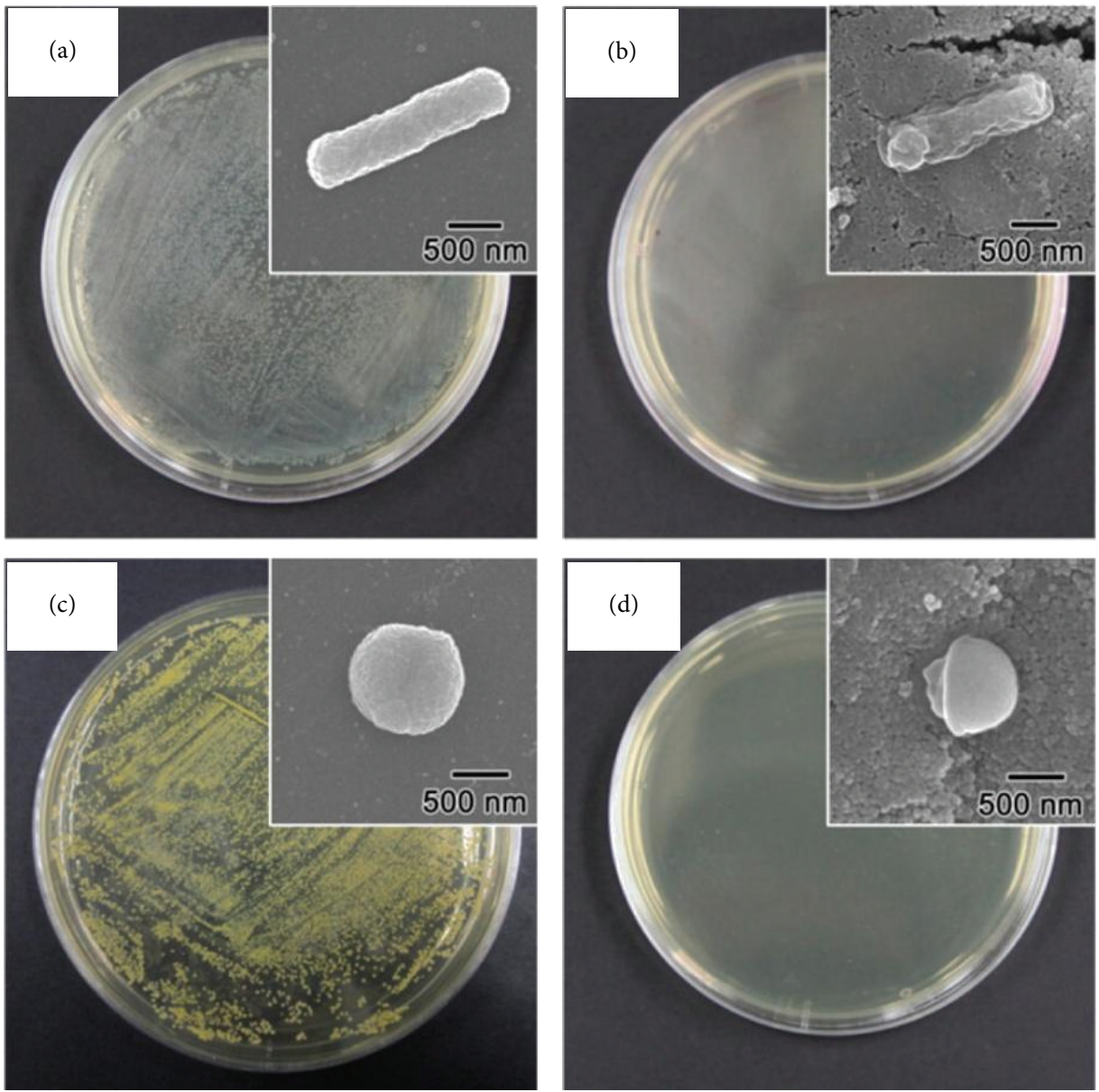

Figure 5: Photographs of colonies of (top) E. coli and (bottom) S. aureus (a, c) without nanoparticles treatment and (b, d) treated with $\mathrm{SiO}_{2}$ -Ag/PRh nanoparticles. Inset figures show the FE-SEM images of a single bacterial cell (left) in the absence of bactericidal agents and (right) treated with the as-prepared nanoparticles. Reproduce from Song et al. with permission from ACS publishers [19].

murine norovirus [96]. Xiang et al. conducted experiments for elucidating the inhibiting role of Ag-NPs against H1N1 influenza A virus. In the report the authors revealed that AgNPs are very effective in inhibiting the normal activity of H1N1 influenza A virus [97]. Furthermore they proposed that Ag-NPs can control the apoptosis of MDCK cells caused by H1N1 influenza A virus. In short almost all of the reported articles suggested the same mechanism which states that AgNPs get adhered to the outer proteins of the viral cells thus ultimately inhibiting the normal function of the viral cells. However authentic mechanism is yet to be established but Ag-NPs are considered to play a pivotal role in future for controlling infectious diseases caused by the viruses [98].

7.4. Composite of Ag-NPs. With the advancement in the field of nanotechnology in several engineered products such as clothing, respirators, water-filters, soaps, contraceptives, antibacterial sprays, and detergent and in numerous household products, silver (Ag-NPs) is used either in pristine form or in combination with other materials for various reasons especially in the biomedical field. With the number of products leveraging the benefits of silver, Ag-NPs have various important applications in the area of medicine from wound dressing to control release of drug at targeted site. For example, Hameed et al. synthesized Ag-NPs silver and gold nanoparticles stabilized with cefuroxime (antibiotic). The composite materials showed various enzyme inhibition activities [99]. Furthermore pristine silver and composite of Ag-NPs have application in the area of electronics transparent conducting films, transparent electrodes for flexible devices, and flexible thin film tandem with solar cells. Several processing techniques have been reported by researchers for the preparation of pristine and composite of Ag-NPs for enhancing its application in various fields.

Usually composite of Ag-NPs is prepared by blending a wide range of natural and synthetic polymers or polymer coating over Ag-NPs which can play vital role in nourishing its various properties. Blended composite of $\mathrm{Ag}$ NPs/polymer can be prepared by solvent casting method along with the use of more versatile technique such as electrospinning (used in the preparation of electrospun hybrid nanofiber scaffolds) $[55,83]$. Li et al. reported that electrospun composite nanofibers comprised of PVA/chitosan/AgNPs can effectively be used as wound dressing agent due 
to its proven effectiveness in inhibiting bacterial growth [100]. More recently Gurhan et al. proposed that by mimicking porous scaffold of collagen with electrospun composite nanofiber functionalized with Ag-NPs can efficiently inhibit bacterial growth. Moreover due to the structural similarities with the skin it can be used as potential scaffolds for skin tissue regeneration [101]. Furthermore electrospun composite nanofiber scaffolds were prepared by blending PEO-PCL/AgNPs. Stabilization of the Ag-NPs was achieved with the help of PEO [102]. Therefore electrospun composite nanofiber scaffolds functionalized with Ag-NPs are considered as an important asset in future medicine. Moreover Zeljka Jovanovic et al. prepared hydrogel containing PVP/Ag-NPs. They revealed that the nanocomposite hydrogel is capable of slow release of $\mathrm{Ag}$, thus paving the way for its use as wound dressing [103]. In one of the published report, the authors unveiled a novel method for the synthesis of composite comprised of oleic-acid coated maghemite nanoparticles embedded in a 1,4-phenylenediamine/phosphotriazine matrix and silver nanoparticles covering the polymer surface. After the assessment of the magnetic properties of their composite, they concluded that the composite containing Ag-NPs has superparamagnetic properties, enabling its easy recovering with the help of external magnet field. The size of the silver nanoparticles (Ag-NPs) was less than $20 \mathrm{~nm}$; finely dispersed Ag-NPs on the polymer surface added the antimicrobial properties to the composite material. Moreover Dallas et al. revealed that by modifying $\mathrm{Ti} / \mathrm{TiO}_{2}$ surfaces with citrate-coated Ag-NPs can efficiently exhibit antibacterial activity. Such kind of composite materials containing Ag-NPs with multifunctional properties has a high scope for use as antimicrobial agent. Furthermore they can also be used in targeted delivery of drug at specific site $[104,105]$.

7.5. Scaffolds of Ag-NPs. Nanoparticles specifically silver nanoparticles (Ag-NPs) are considered to be of prime importance due the emergence of antibiotic resistance bacteria [106]. These antibiotic resistant bacteria pose great threat to the human beings and their properties. Consumer products and devices containing silver are already in use in medicinal field such as prostheses, catheters, vascular grafts, and as wound dressings [107]. Silver (Ag-NPs) is very effective antimicrobial agents and plays a vital role in wound healing [108]. Silver nanoparticles (Ag-NPs) bind to the sulphur present in the protein comprising the cell wall of the microbes and phosphorous in the DNA, thus retarding their normal function. They also affect the bacterial respiratory system. Wide range of composite materials containing silver nanoparticles (Ag-NPS) has been prepared simply by blending them with various natural and synthetic polymers like cellulose, chitosan, polystyrene, acrylic acid [109], PCL, [110] gelatin, PVP [55], PEO [102, 111], and so forth. Furthermore other polymeric materials such as polyurethane, chitin, and its derivatives are widely used as wound dressings scaffolds in combination with Ag-NPs due to their famous antimicrobial and biocompatible properties $[112,113]$.

7.6. Wound Dressing. Wound dressings (bandages) functionalized with silver nanoparticles (Ag-NPs) are commercially available and are frequently used for medicinal purpose for curing various infections such as burn wounds, toxic epidermal necrolysis, Steven-Johnson syndrome, chronic ulcers, and pemphigus [10]. In typical bandages (wound dressings) Ag-NPs are coated on the surface of polyethylene layer. Experiments have proven the superior wound healing properties of the Ag-NPs coated bandages (wound dressing) as compared to the wound dressing without Ag-NPs. Such wound dressing has the ability to prevent infections along with minimizing the healing time without any side effect [8]. In an article published on Ag-NPs, researchers concluded that bandages (wound dressing) containing Ag-NPs minimize the healing time of burns wounds. However no difference in healing time of deep burns wounds was found [8]. In a report published by research group, the authors proposed that dressing comprised of chitosan/silver nanoparticles (Cs/Ag-NPs) demonstrated superior healing rates contrary to the conventional wound dressing; furthermore they used chitosan as control in their experiments. Using Ag-NPs in wound dressing can be helpful in eradicating problems related to skin [20]. In one of the published report, researchers have incorporated Ag-NPs into chitin scaffolds which were later used as wound dressing agent. From their experiments they concluded that the wound healing and antimicrobial efficacy of chitin are further enhanced by the incorporation of Ag-NP [10, 112]. Furthermore in another published article researchers after their extensive study have revealed that hydrogel made of $\beta$-chitin and Ag-NPs can be effective in preventing various infection that can occur to wounds [114]. In another published article, researchers have reported that incorporating Ag-NPs (having size less than $20 \mathrm{~nm}$ ) in guar gum, [110] a new cationic biopolymer has shown quicker healing and improved cosmetic appearance. Furthermore the biopolymer matrix functioned as hydrated surface that helped in cell proliferation. The antimicrobial activity of wound dressing functionalized with Ag-NPs is largely dependent on the concentration, release of silver along with the distribution and its degree of wettability [115]. The importance of Ag-NPs in bandages (wound dressing) has been acknowledged by the scientific community and can be helpful in paving the way for the fabrication of new materials containing Ag-NPs that can ultimately be used in future medicine [5].

7.7. Implanted Materials. Just before the beginning of the 21th century, artificial heart valve made of silicone (Silzone) coated with Ag-NPs was prepared for controlling endocarditis (an inflammation which occurs after surgery) [116]. The idea behind using Ag-NPs coating on the artificial silicone valve was to eliminate the dangers of microbial infections. Ag-NPs are considered to be an efficient coating agent on medicinal devices due to its proven antimicrobial activity. In one of the reported study researchers proposed that diamond-like carbon with Ag-NPs incorporated in the matrix can be useful if used as coating on the medicinal devices such as heart valves and stents [117]. Researchers also reported that the incorporation of Ag-NPs into poly(methyl methacrylate) ((PMMA) bone cement) can be helpful in hip and knee joint implantation; presence of Ag-NPs will give the added advantage of preventing microbial infections [118]. Ag-NPs are becoming 


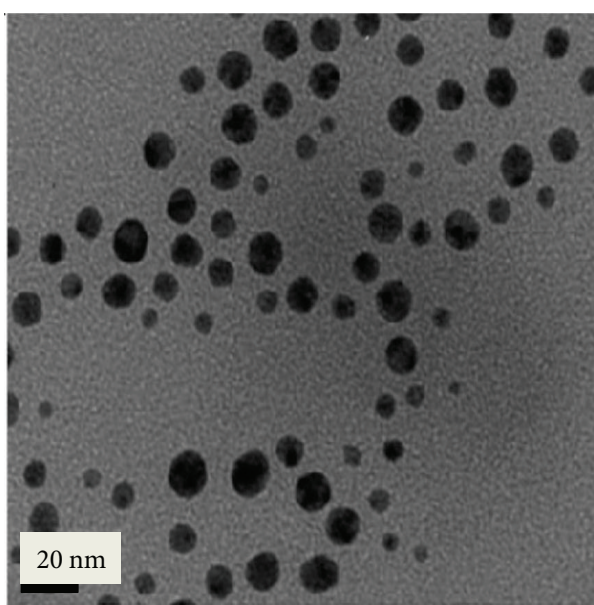

(a)

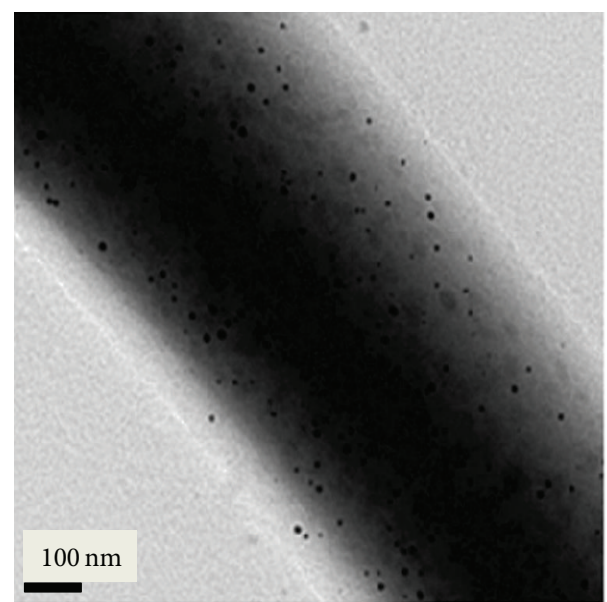

(b)

FIGURE 6: TEM images of (a) free silver nanoparticles and (b) silver nanoparticles distributed to the PHBV nanofibrous scaffolds (PHBV/Ag 1.0). Reproduce from Xing et al. with permission from ACS publishers [20].

important tool in surgery for preventing microbial infections; catheters impregnated with Ag-NPs are proving to be helpful in overcoming infections related catheters which are being used during surgery [119]. Xing et al. fabricated (poly-(-3hydroxybutyrate-co-3-hydroxyvalerate) PHBV nanofibrous scaffolds containing Ag-NPs. After extensive study on both osteoblast (bone cells) and fibroblast (skin cells) cultured on the PBHV/Ag-NPs hybrid nanofiber scaffolds they concluded that such scaffolds can be useful in bone and skin tissue regeneration (Figure 6) [20]. By fabricating the surface of structure of the bone implants devices and scaffolds with Ag-NPs it can overcome the risk associated with implantation surgery. $\mathrm{Wu}$ et al. concluded that the $\mathrm{Ag}-\mathrm{NP} / \mathrm{nHA} / \mathrm{TiO}_{2} / \mathrm{PA} 66 \mathrm{com}-$ posite scaffold having porous structure with antimicrobial properties can be effective in control release of Ag at targeted bone implanted site. Apart from the antimicrobial activity the composite porous scaffolds with enhanced mechanical properties will provide favorable environment for adhesion and proliferation of the cultured cells [120]. Ye et al. conducted experiment for assessing the role of $\mathrm{Ag}-\mathrm{nHAnTiO} \mathrm{O}_{2} / \mathrm{PA} 66$ membrane on MG63 osteoblast like cells in vitro. In their study they used nHA/PA66 and polytetrafluroethylene (ePTFE) membranes as control. From the obtained results the authors concluded that Ag-nHA-nTiO $2 / \mathrm{PA} 66$ membrane had no adverse effect on the adhesion and proliferation of MG63 (osteoblast like) cells and the membranes simultaneously present tissue compatibility. Therefore Ag-nHA-nTiO $2 / \mathrm{PA} 66$ membrane can be used for bone tissue regeneration [121]. Furthermore an extension of the work reported by Ye et al., Zhang et al. conducted experiments on rats and revealed that Ag-nHAnTiO $/ 2$ PA66 membrane underwent osteogenesis process [122]. Saravanan et al. prepared CS/nHAp/Ag-NPs tricomposite scaffold; after conducting various experiments for the evaluation of its antimicrobial and biocompatible nature they revealed that the tricomposite CS/nHAp/AgNPs scaffold was effective in preventing bacterial infection. Furthermore the tricomposite (CS/nHAp/Ag-NPs) scaffolds provided favorable environment for adhesion and proliferation of rat osteoprogenitor cells and human osteosarcoma cell lines [123]. Moreover Xie et al. published an article in which they proposed that Ti surface coated with HA/CS/AgNPs can be used as artificial bone implanting material due its multifunctional properties. Ag-NPs will act as antimicrobial agent. Chitosan will increase the biocompatibility and HA will help in providing native environment for the proliferation of the bone cells (osteoblastic cells; see Figure 7) [21, 123, 124].

\section{Future Prospects}

The importance of Ag-NPs in medicine is known to everyone. Ag-NPs have played pivotal role in inhibiting various infectious disease caused by microbes in combination with simultaneous helping in the burn wounds healing process, by preventing wound from infections caused by microbes. Furthermore Ag-NPs are also known for their anti-inflammatory and antiviral activity. Apart from its widely known antimicrobial activity it has remarkable application in biological field as well as in other research fields such as electrochemistry, biochemistry, nanoprism synthesis, garments, detergents and soap industry, involved in devising water purification system, and surgical instrument. Moreover Ag-NPs have a bright future in devices that can be used as artificial implants in future and minimizing the dependency on antibiotics. Recently researchers revealed novel biological application of Ag-NPs; the authors proposed that aqueous solution of $\mathrm{Ag}$-NPs can be helpful in building new pharmaceutical and therapeutic agents. For example, in one of the published article the authors reported that aqueous solution of Ag-NPs can be used for curing the interstitial cystitis (inflammation of the bladder). They used mouse model for the assessment of the anti-inflammatory effect [119]. The full potential of this technology is yet to be investigated. A reliable mechanism responsible for the impressive biological activity of Ag-NPs is yet to be established and is considered to be a key factor 


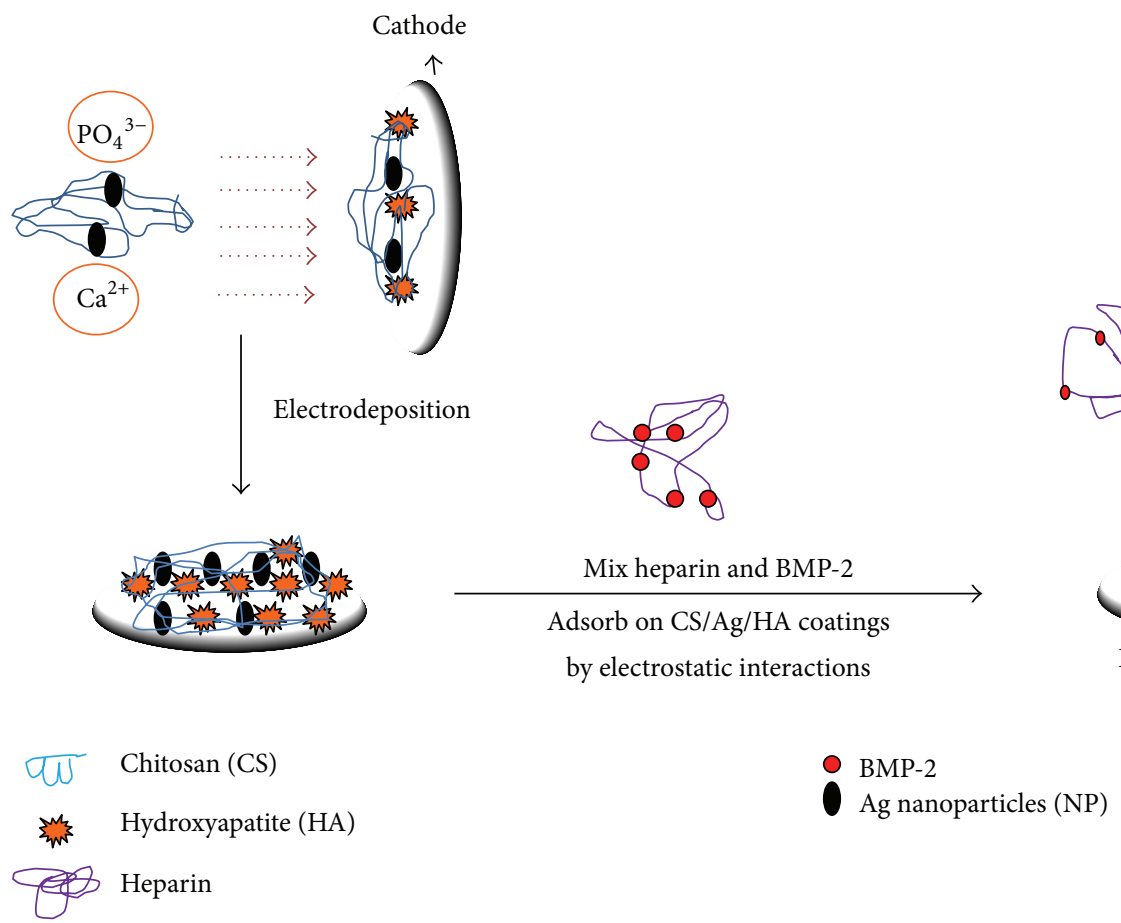

FIGURE 7: Titanium surface modified with growth factors, HA chitosan, and Ag-NPs. Reproduce from Xie et al. with permission from ACS publishers [21].

in future research. There is room for controlling the release of Ag and improving the stability of Ag-NPs used in various devices for various purposes especially in medicinal field. Finally, with the widespread use of Ag-NPs, addressing issue relating to the cytotoxicity is the cry of the day.

\section{Conclusion}

Ag-NPs are regarded as important addition in the area of nanomaterials because of the diversity it provides in terms of application in various walk of science. Due to their anti-inflammatory and antimicrobial activity Ag-NPs have diverted attraction of the masses towards themselves to be used as implanted material in artificial organs. Ag-NPs have proven it worth in inhibiting the microbial proliferation and microbial infection. Furthermore Ag-NPs have added a new dimension in the field of medicine concerning wound dressing and artificial implantation and in preventing postsurgical contamination caused by microbes. Apart from that Ag-NPs play a pivotal role and are considered as important ingredients in the preparation of commercially used products in industries.

\section{Conflict of Interests}

It is hereby stated that the authors have no conflict of interests in publishing this paper.

\section{Acknowledgments}

This study was supported by the Basic Research Laboratory Program (NRF 2011-0020264) and the General Research
Program (no. 2013 R1A1A 2005148) from the ministry of Education, Science and Technology of Korea.

\section{References}

[1] Y. Ju-Nam and J. R. Lead, "Manufactured nanoparticles: an overview of their chemistry, interactions and potential environmental implications," Science of the Total Environment, vol. 400, no. 1-3, pp. 396-414, 2008.

[2] A.-H. Lu, E. L. Salabas, and F. Schüth, "Magnetic nanoparticles: synthesis, protection, functionalization, and application," Angewandte Chemie (International Edition), vol. 46, no. 8, pp. 1222 1244, 2007.

[3] M. De, P. S. Ghosh, and V. M. Rotello, "Applications of nanoparticles in biology," Advanced Materials, vol. 20, no. 22, pp. 4225-4241, 2008.

[4] P. S. Ghosh and C. Rajib, "Core/shell nanoparticles: classes, properties, synthesis mechanisms, characterization, and applications," Chemical Reviews, vol. 112, no. 4, pp. 2373-2433, 2012.

[5] V. K. Sharma, R. A. Yngard, and Y. Lin, "Silver nanoparticles: green synthesis and their antimicrobial activities," Advances in Colloid and Interface Science, vol. 145, no. 1-2, pp. 83-96, 2009.

[6] Y. A. Krutyakov, A. A. Kudrinskiy, A. Y. Olenin, and G. V. Lisichkin, "Synthesis and properties of silver nanoparticles: advances and prospects," Russian Chemical Reviews, vol. 77, no. 3, pp. 233-257, 2008.

[7] D. R. Monteiro, L. F. Gorup, A. S. Takamiya, A. C. Ruvollo-Filho, E. R. D. Camargo, and D. B. Barbosa, "The growing importance of materials that prevent microbial adhesion: antimicrobial effect of medical devices containing silver," International Journal of Antimicrobial Agents, vol. 34, no. 2, pp. 103-110, 2009. 
[8] M. Ahamed, M. S. AlSalhi, and M. K. J. Siddiqui, "Silver nanoparticle applications and human health," Clinica Chimica Acta, vol. 411, no. 23-24, pp. 1841-1848, 2010.

[9] J. Fabrega, S. N. Luoma, C. R. Tyler, T. S. Galloway, and J. R. Lead, "Silver nanoparticles: behaviour and effects in the aquatic environment," Environment International, vol. 37, no. 2, pp. 517531, 2011.

[10] T. Quang Huy, N. van Quy, and L. Anh-Tuan, "Silver nanoparticles: synthesis, properties, toxicology, applications and perspectives," Advances in Natural Sciences: Nanoscience and Nanotechnology, vol. 4, no. 3, p. 033001, 2013.

[11] J. Yu and X. Zhou, "Synthesis of dendritic silver nanoparticles and their applications as SERS substrates," Advances in Materials Science and Engineering, vol. 2013, Article ID 519294, 4 pages, 2013.

[12] Y. Sun and Y. Xia, "Shape-controlled synthesis of gold and silver nanoparticles," Science, vol. 298, no. 5601, pp. 2176-2179, 2002.

[13] D. Kim, S. Jeong, and J. Moon, "Synthesis of silver nanoparticles using the polyol process and the influence of precursor injection," Nanotechnology, vol. 17, no. 16, pp. 4019-4024, 2006.

[14] M. Chen, Y.-G. Feng, X. Wang, T.-C. Li, J.-Y. Zhang, and D.J. Qian, "Silver nanoparticles capped by oleylamine: formation, growth, and self-organization," Langmuir, vol. 23, no. 10, pp. 5296-5304, 2007.

[15] S. Mukherji and S. Agnihotri, "Size-controlled silver nanoparticles synthesized over the range 5-100 nm using the same protocol and their antibacterial efficacy," RSC Advances, vol. 4, no. 8, pp. 3974-3983, 2014.

[16] H. Zhang and C. Zhang, "Transport of silver nanoparticles capped with different stabilizers in water saturated porous media," Journal of Materials and Environmental Science, vol. 5, no. 1, pp. 231-236, 2014.

[17] G. Sharma, A. R. Sharma, M. Kurian, R. Bhavesh, J. S. Nam, and S. S. Lee, "Green synthesis of silver nanoparticle using Myristica fragrans (nutmeg) seed extract and its biological activity," Digest Journal of Nanomaterials and Biostructures, vol. 9, no. 1, pp. 325332, 2014.

[18] M. M. Shahjamali, M. Bosman, S. Cao et al., "Gold coating of silver nanoprisms," Advanced Functional Materials, vol. 22, no. 4, pp. 849-854, 2012.

[19] J. Song, H. Kim, Y. Jang, and J. Jang, "Enhanced antibacterial activity of silver/polyrhodanine-composite-decorated silica nanoparticles," Applied Materials \& Interfaces, vol. 5, no. 22, pp. 11563-11568, 2013.

[20] Z.-C. Xing, W.-P. Chae, J.-Y. Baek, M.-J. Choi, Y. Jung, and I.K. Kang, "In vitro assessment of antibacterial activity and cytocompatibility of silver-containing PHBV nanofibrous scaffolds for tissue engineering," Biomacromolecules, vol. 11, no. 5, pp. 1248-1253, 2010.

[21] C. M. Xie, X. Lu, K. F. Wang et al., "Silver nanoparticles and growth factors incorporated hydroxyapatite coatings on metallic implant surfaces for enhancement of osteoinductivity and antibacterial properties," ACS Applied Materials \& Interfaces, vol. 6, no. 11, pp. 8580-8589, 2014.

[22] D. K. Lee and Y. S. Kang, "Synthesis of silver nanocrystallites by a new thermal decomposition method and their characterization," ETRI Journal, vol. 26, no. 3, pp. 252-256, 2004.

[23] J. H. Jung, H. Cheol Oh, H. Soo Noh, J. H. Ji, and S. Soo Kim, "Metal nanoparticle generation using a small ceramic heater with a local heating area," Journal of Aerosol Science, vol. 37, no. 12, pp. 1662-1670, 2006.
[24] D. C. Tien, K. H. Tseng, C. Y. Liao, J. C. Huang, and T. T. Tsung, "Discovery of ionic silver in silver nanoparticle suspension fabricated by arc discharge method," Journal of Alloys and Compounds, vol. 463, no. 1-2, pp. 408-411, 2008.

[25] K.-H. Tseng, H.-L. Lee, C.-Y. Liao, K.-C. Chen, and H.-S. Lin, "Rapid and efficient synthesis of silver nanofluid using electrical discharge machining," Journal of Nanomaterials, vol. 2013, Article ID 174939, 6 pages, 2013.

[26] K.-H. Tseng, H.-L. Lee, C.-Y. Liao, K.-C. Chen, and H.-S. Lin, "Rapid and efficient synthesis of silver nanofluid using electrical discharge machining," Journal of Nanomaterials, vol. 2013, Article ID 174939, 6 pages, 2013.

[27] A. J. Christy and M. Umadevi, "Synthesis and characterization of monodispersed silver nanoparticles," Advances in Natural Sciences: Nanoscience and Nanotechnology, vol. 3, no. 3, Article ID 035013, 4 pages, 2012.

[28] S. K. Ghosh, S. Kundu, M. Mandal, S. Nath, and T. Pal, "Studies on the evolution of silver nanoparticles in micelle by UVphotoactivation," Journal of Nanoparticle Research, vol. 5, no. 56, pp. 577-587, 2003.

[29] L. Huang, M. L. Zhai, D. W. Long et al., "UV-induced synthesis, characterization and formation mechanism of silver nanoparticles in alkalic carboxymethylated chitosan solution," Journal of Nanoparticle Research, vol. 10, no. 7, pp. 1193-1202, 2008.

[30] L. Balan, R. Schneider, C. Turck, D. Lougnot, and F. MorletSavary, "Photogenerating silver nanoparticles and polymer nanocomposites by direct activation in the near infrared," Journal of Nanomaterials, vol. 2012, Article ID 512579, 6 pages, 2012.

[31] M. Sakamoto, M. Fujistuka, and T. Majima, "Light as a construction tool of metal nanoparticles: synthesis and mechanism," Journal of Photochemistry and Photobiology C: Photochemistry Reviews, vol. 10, no. 1, pp. 33-56, 2009.

[32] L. Sintubin, W. Verstraete, and N. Boon, "Biologically produced nanosilver: current state and future perspectives," Biotechnology and Bioengineering, vol. 109, no. 10, pp. 2422-2436, 2012.

[33] A. K. Suresh, D. A. Pelletier, W. Wang et al., "Silver nanocrystallites: biofabrication using shewanella oneidensis, and an evaluation of their comparative toxicity on gram-negative and gram-positive bacteria," Environmental Science and Technology, vol. 44, no. 13, pp. 5210-5215, 2010.

[34] A. M. Fayaz, K. Balaji, M. Girilal, R. Yadav, P. T. Kalaichelvan, and R. Venketesan, "Biogenic synthesis of silver nanoparticles and their synergistic effect with antibiotics: a study against gram-positive and gram-negative bacteria," Nanomedicine: Nanotechnology, Biology, and Medicine, vol. 6, no. 1, pp. 103-109, 2010.

[35] V. Thirumalai Arasu, D. Prabhu, and M. Soniya, "Stable silver nanoparticle synthesizing methods and its applications," Journal of Biosciences Research, vol. 1, no. 4, pp. 259-270, 2010.

[36] N. Pugazhenthiran, S. Anandan, G. Kathiravan, N. K. Udaya Prakash, S. Crawford, and M. Ashokkumar, "Microbial synthesis of silver nanoparticles by Bacillus sp," Journal of Nanoparticle Research, vol. 11, no. 7, pp. 1811-1815, 2009.

[37] K. P. Venkata Subbaiah and N. Savithramma, "Synthesis of silver nanoparticles and antimicrobial activity from Cadaba fruticosa-an important ethnomedicinal plant to treat Vitiligo of kurnool district, andhra pradesh," Indo American Journal of Pharmaceutical Research, vol. 3, no. 12, pp. 1285-1292, 2013.

[38] X. Yang, A. P. Gondikas, S. M. Marinakos et al., "Mechanism of silver nanoparticle toxicity is dependent on dissolved silver 
and surface coating in Caenorhabditis elegans," Environmental Science \& Technology, vol. 46, no. 2, pp. 1119-1127, 2012.

[39] H. J. Yen, S. H. Hsu, and C. L. Tsai, "Cytotoxicity and immunological response of gold and silver nanoparticles of different sizes," Small, vol. 5, no. 13, pp. 1553-1561, 2009.

[40] C. M. Powers, A. R. Badireddy, I. T. Ryde, F. J. Seidler, and T. A. Slotkin, "Silver nanoparticles compromise neurodevelopment in PC12 cells: critical contributions of silver Ion, particle size, coating, and composition," Environmental Health Perspectives, vol. 119, no. 1, pp. 37-44, 2011.

[41] I. Montes-Burgos, D. Walczyk, P. Hole, J. Smith, I. Lynch, and K. Dawson, "Characterisation of nanoparticle size and state prior to nanotoxicological studies," Journal of Nanoparticle Research, vol. 12, no. 1, pp. 47-53, 2010.

[42] K. A. Dawson, S. Anguissola, and I. Lynch, "The need for in situ characterisation in nanosafety assessment: funded transnational access via the QNano research infrastructure," Nanotoxicology, vol. 7, no. 3, pp. 346-349, 2013.

[43] B. Nowack, H. F. Krug, and M. Height, "120 years of nanosilver history: implications for policy makers," Environmental Science and Technology, vol. 45, no. 4, pp. 1177-1183, 2011.

[44] T. Walser, E. Demou, D. J. Lang, and S. Hellweg, "Prospective environmental life cycle assessment of nanosilver T-shirts," Environmental Science and Technology, vol. 45, no. 10, pp. 45704578, 2011.

[45] S. A. Blaser, M. Scheringer, M. MacLeod, and K. Hungerbühler, "Estimation of cumulative aquatic exposure and risk due to silver: contribution of nano-functionalized plastics and textiles," Science of the Total Environment, vol. 390, no. 2-3, pp. 396-409, 2008.

[46] T. M. Benn and P. Westerhoff, "Nanoparticle silver released into water from commercially available sock fabrics," Environmental Science and Technology, vol. 42, no. 11, pp. 4133-4139, 2008.

[47] A. I. Freeman, L. J. Halladay, and P. Cripps, "The effect of silver impregnation of surgical scrub suits on surface bacterial contamination," The Veterinary Journal, vol. 192, no. 3, pp. 489493, 2012.

[48] Q. Li, S. Mahendra, D. Y. Lyon et al., "Antimicrobial nanomaterials for water disinfection and microbial control: potential applications and implications," Water Research, vol. 42, no. 18, pp. 4591-4602, 2008.

[49] J. Liu and R. H. Hurt, "Ion release kinetics and particle persistence in aqueous nano-silver colloids," Environmental Science \& Technology, vol. 44, no. 6, pp. 2169-2175, 2010.

[50] L. Geranio, M. Heuberger, and B. Nowack, "The behavior of silver nanotextiles during washing," Environmental Science and Technology, vol. 43, no. 21, pp. 8113-8118, 2009.

[51] S. Y. Yeo and S. H. Jeong, "Preparation and characterization of polypropylene/silver nanocomposite fibers," Polymer International, vol. 52, no. 7, pp. 1053-1057, 2003.

[52] M. E. Samberg, P. E. Orndorff, and N. A. Monteiro-Riviere, "Antibacterial efficacy of silver nanoparticles of different sizes, surface conditions and synthesis methods," Nanotoxicology, vol. 5, no. 2, pp. 244-253, 2011.

[53] M. K. Cushen, J. Kerry, M. Morris, M. Cruz-Romero, and E. Cummins, "Nanotechnologies in the food industry-recent developments, risks and regulation," Trends in Food Science \& Technology, vol. 24, no. 1, pp. 30-46, 2012.

[54] D. Roe, B. Karandikar, N. Bonn-Savage, B. Gibbins, and J.B. Roullet, "Antimicrobial surface functionalization of plastic catheters by silver nanoparticles," Journal of Antimicrobial Chemotherapy, vol. 61, no. 4, pp. 869-876, 2008.
[55] C. L. Doolette, M. J. McLaughlin, J. K. Kirby et al., “Transformation of PVP coated silver nanoparticles in a simulated wastewater treatment process and the effect on microbial communities," Chemistry Central Journal, vol. 7, no. 1, article 46, 2013.

[56] T. Thiwawong, K. Onlaor, and B. Tunhoo, "A humidity sensor based on silver nanoparticles thin film prepared by electrostatic spray deposition process," Advances in Materials Science and Engineering, vol. 2013, Article ID 640428, 7 pages, 2013.

[57] V. Bastys, I. Pastoriza-Santos, B. Rodíguez-González, R. Vaisnoras, and L. M. Liz-Marzán, "Formation of silver nanoprisms with surface plasmons at communication wavelengths," Advanced Functional Materials, vol. 16, no. 6, pp. 766-773, 2006.

[58] A. Callegari, D. Tonti, and M. Chergui, "Photochemically grown silver nanoparticles with wavelength-controlled size and shape," Nano Letters, vol. 3, no. 11, pp. 1565-1568, 2003.

[59] R. C. Jin, Y. C. Cao, E. Hao, G. S. Métraux, G. C. Schatz, and C. A. Mirkin, "Controlling anisotropic nanoparticle growth through plasmon excitation," Nature, vol. 425, no. 6957, pp. 487-490, 2003.

[60] C. Loo, A. Lowery, N. Halas, J. West, and R. Drezek, "Immunotargeted nanoshells for integrated cancer imaging and therapy," Nano Letters, vol. 5, no. 4, pp. 709-711, 2005.

[61] M. Ip, S. L. Lui, V. K. M. Poon, I. Lung, and A. Burd, "Antimicrobial activities of silver dressings: an in vitro comparison," Journal of Medical Microbiology, vol. 55, no. 1, pp. 59-63, 2006.

[62] S. Sarkar, A. D. Jana, S. K. Samanta, and G. Mostafa, "Facile synthesis of silver nano particles with highly efficient antimicrobial property," Polyhedron, vol. 26, no. 15, pp. 4419-4426, 2007.

[63] W. R. Hill and D. M. Pillsbury, Argyria: The Pharmacology of Silver, Williams \& Wilkins Company, Baltimore, Md, USA, 1939.

[64] N. R. Panyala, E. M. Pena-Mendez, and J. Havel, "Silver or silver nanoparticles: a hazardous threat to the environment and human health?" Journal of Applied Biomedicine, vol. 6, no. 3, pp. 117-129, 2008.

[65] J. P. Marshall II and R. P. Schneider, "Systemic argyria secondary to topical silver nitrate," Archives of Dermatology, vol. 113, no. 8, pp. 1077-1079, 1977.

[66] B. Chudasama, A. K. Vala, N. Andhariya, R. V. Upadhyay, and R. V. Mehta, "Enhanced antibacterial activity of bifunctional $\mathrm{Fe}_{3} \mathrm{O}_{4}$-Ag core-shell nanostructures," Nano Research, vol. 2, no. 12, pp. 955-965, 2009.

[67] X. Zhang, H. Niu, J. Yan, and Y. Cai, "Immobilizing silver nanoparticles onto the surface of magnetic silica composite to prepare magnetic disinfectant with enhanced stability and antibacterial activity," Colloids and Surfaces A: Physicochemical and Engineering Aspects, vol. 375, no. 1-3, pp. 186-192, 2011.

[68] J. Dong, Z. Xu, and S. M. Kuznicki, "Magnetic multi-functional nano composites for environmental applications," Advanced Functional Materials, vol. 19, no. 8, pp. 1268-1275, 2009.

[69] L. Mpenyana-Monyatsi, N. H. Mthombeni, M. S. Onyango, and M. N. B. Momba, "Cost-effective filter materials coated with silver nanoparticles for the removal of pathogenic bacteria in groundwater," International Journal of Environmental Research and Public Health, vol. 9, no. 1, pp. 244-271, 2012.

[70] J. H. Ji, J. H. Jung, S. S. Kim et al., "Twenty-eight-day inhalation toxicity study of silver nanoparticles in Sprague-Dawley rats," Inhalation Toxicology, vol. 19, no. 10, pp. 857-871, 2007. 
[71] J. H. Sung, J. H. Ji, J. U. Yoon et al., "Lung function changes in Sprague-Dawley rats after prolonged inhalation exposure to silver nanoparticles," Inhalation Toxicology, vol. 20, no. 6, pp. 567-574, 2008.

[72] H.-Y. Lee, Y.-J. Choi, E.-J. Jung et al., "Genomics-based screening of differentially expressed genes in the brains of mice exposed to silver nanoparticles via inhalation," Journal of Nanoparticle Research, vol. 12, no. 5, pp. 1567-1578, 2010.

[73] L. V. Stebounova, A. Adamcakova-Dodd, J. S. Kim et al., "Nanosilver induces minimal lung toxicity or inflammation in a subacute murine inhalation model," Particle and Fibre Toxicology, vol. 8, article 5, 2011.

[74] Y. S. Kim, J. S. Kim, H. S. Cho et al., “Twenty-eight-day oral toxicity, genotoxicity, and gender-related tissue distribution of silver nanoparticles in Sprague-Dawley rats," Inhalation Toxicology, vol. 20, no. 6, pp. 575-583, 2008.

[75] M. E. Samberg, S. J. Oldenburg, and N. A. Monteiro-Riviere, "Evaluation of silver nanoparticle toxicity in skin in vivo and keratinocytes in vitro," Environmental Health Perspectives, vol. 118, no. 3, pp. 407-413, 2010.

[76] C. Lorenz, H. Hagendorfer, N. Von Goetz et al., "Nanosized aerosols from consumer sprays: experimental analysis and exposure modeling for four commercial products," Journal of Nanoparticle Research, vol. 13, no. 8, pp. 3377-3391, 2011.

[77] A. B. G. Lansdown, "A review of the use of silver in wound care: facts and fallacies," British Journal of Nursing, vol. 13, no. 6, pp. S6-S19, 2004.

[78] Q. L. Feng, J. Wu, G. Q. Chen, F. Z. Cui, T. N. Kim, and J. O. Kim, "A mechanistic study of the antibacterial effect of silver ions on Escherichia coli and Staphylococcus aureus," Journal of Biomedical Materials Research, vol. 52, no. 4, pp. 662-668, 2000.

[79] K. K. Y. Wong and X. Liu, "Silver nanoparticles-the real "silver bullet” in clinical medicine?” MedChem Comm, vol. 1, no. 2, pp. 125-131, 2010.

[80] B. Reidy, A. Haase, A. Luch, K. A. Dawson, and I. Lynch, "Mechanisms of silver nanoparticle release, transformation and toxicity: a critical review of current knowledge and recommendations for future studies and applications," Materials, vol. 6, no. 6, pp. 2295-2350, 2013.

[81] L. G. Ovington, “The truth about silver," Ostomy/Wound Management, vol. 50, no. 9, pp. 1-10, 2004.

[82] M. Ul-Islam, A. Shehzad, S. Khan, W. A. Khattak, M. W. Ullahl, and J. K. Park, "Antimicrobial and biocompatible properties of nanomaterials," Journal of Nanoscience and Nanotechnology, vol. 14, no. 1, pp. 780-791, 2014.

[83] C. Marambio-Jones and E. M. V. Hoek, "A review of the antibacterial effects of silver nanomaterials and potential implications for human health and the environment," Journal of Nanoparticle Research, vol. 12, no. 5, pp. 1531-1551, 2010.

[84] I. Sondi and B. Salopek-Sondi, "Silver nanoparticles as antimicrobial agent: a case study on E. coli as a model for Gramnegative bacteria," Journal of Colloid and Interface Science, vol. 275, no. 1, pp. 177-182, 2004.

[85] J. R. Morones, J. L. Elechiguerra, A. Camacho et al., "The bactericidal effect of silver nanoparticles," Nanotechnology, vol. 16, no. 10, pp. 2346-2353, 2005.

[86] S. Shrivastava, T. Bera, A. Roy, G. Singh, P. Ramachandrarao, and D. Dash, "Characterization of enhanced antibacterial effects of novel silver nanoparticles," Nanotechnology, vol. 18, no. 22, Article ID 225103, 2007.
[87] S. Pal, Y. K. Tak, and J. M. Song, "Does the antibacterial activity of silver nanoparticles depend on the shape of the nanoparticle? A study of the gram-negative bacterium Escherichia coli," Applied and Environmental Microbiology, vol. 73, no. 6, pp. 17121720, 2007.

[88] D. A. Enoch, H. A. Ludlam, and N. M. Brown, "Invasive fungal infections: a review of epidemiology and management options," Journal of Medical Microbiology, vol. 55, no. 7, pp. 809-818, 2006.

[89] K.-J. Kim, W. S. Sung, S.-K. Moon, J.-S. Choi, J. G. Kim, and D. G. Lee, "Antifungal effect of silver nanoparticles on dermatophytes," Journal of Microbiology and Biotechnology, vol. 18, no. 8, pp. 1482-1484, 2008.

[90] D. R. Monteiro, S. Silva, M. Negri et al., "Silver colloidal nanoparticles: effect on matrix composition and structure of Candida albicans and Candida glabrata biofilms," Journal of Applied Microbiology, vol. 114, no. 4, pp. 1175-1183, 2013.

[91] R. J. Coker, B. M. Hunter, J. W. Rudge, M. Liverani, and P. Hanvoravongchai, "Emerging infectious diseases in southeast Asia: regional challenges to control," The Lancet, vol. 377, no. 9765, pp. 599-609, 2011.

[92] J. L. Elechiguerra, J. L. Burt, J. R. Morones et al., "Interaction of silver nanoparticles with HIV-1," Journal of Nanobiotechnology, vol. 3, article 6, 2005.

[93] H. H. Lara, N. V. Ayala-Nuñez, L. Ixtepan-Turrent, and C. Rodriguez-Padilla, "Mode of antiviral action of silver nanoparticles against HIV-1," Journal of Nanobiotechnology, vol. 8, article $1,2010$.

[94] L. Sun, A. K. Singh, K. Vig, S. R. Pillai, and S. R. Singh, "Silver nanoparticles inhibit replication of respiratory syncytial virus," Journal of Biomedical Nanotechnology, vol. 4, no. 2, pp. 149-158, 2008.

[95] J. V. Rogers, C. V. Parkinson, Y. W. Choi, J. L. Speshock, and S. M. Hussain, "A preliminary assessment of silver nanoparticle inhibition of monkeypox virus plaque formation," Nanoscale Research Letters, vol. 3, no. 4, pp. 129-133, 2008.

[96] B. De Gusseme, L. Sintubin, L. Baert et al., "Biogenic silver for disinfection of water contaminated with viruses," Applied and Environmental Microbiology, vol. 76, no. 4, pp. 1082-1087, 2010.

[97] D. Xiang, Y. Zheng, W. Duan et al., "Inhibition of A/Human/Hubei/3/2005 (H3N2) influenza virus infection by silver nanoparticles in vitro and in vivo," International Journal of Nanomedicine, vol. 8, pp. 4103-4113, 2013.

[98] S. Galdiero, A. Falanga, M. Vitiello, M. Cantisani, V. Marra, and M. Galdiero, "Silver nanoparticles as potential antiviral agents," Molecules, vol. 16, no. 10, pp. 8894-8918, 2011.

[99] A. Hameed, S. Fatima, F. U. Rahman et al., "Synergistic enzyme inhibition effect of cefuroxime by conjugation with gold and silver," New Journal of Chemistry, vol. 38, no. 4, pp. 1641-1646, 2014.

[100] C. Li, R. Fu, C. P. Yu et al., "Silver nanoparticle/chitosan oligosaccharide/poly(vinyl alcohol) nanofibers as wound dressings: a preclinical study," International Journal of Nanomedicine, vol. 8, no. 1, pp. 4131-4145, 2013.

[101] M. T. O. Gurhan Uzunalan, S. Dincer, and K. Tuzlakoglu, "A newly designed collagen-based bilayered scaffold for skin tissue regeneration," Journal of Composites and Biodegradable Polymers, vol. 1, no. 8, pp. 8-15, 2013.

[102] P. G. P. Dubey, "A novel and facile approach for in situ synthesis of silver nanoparticles in nanofibers for antimicrobial wound dressing," in Proceedings of the World Innovation Conference, 2014. 
[103] A. R. Zeljka Jovanovic, J. Stojkovska, B. Nikolic, B. Obradovic, Z. Kacarevic-Popovic, and V. Miskovic-Stankovic, "Long-lasting antimicrobial wound dressings," Society of Plastic Engineering, no. 10, p. 5186, 2013.

[104] P. Dallas, J. Tucek, D. Jancik, M. Kolar, A. Panacek, and R. Zboril, "Magnetically controllable silver nanocomposite with multifunctional phosphotriazine matrix and high antimicrobial activity," Advanced Functional Materials, vol. 20, no. 14, pp. 2347-2354, 2010.

[105] C. Y. Flores, C. Diaz, A. Rubert et al., "Spontaneous adsorption of silver nanoparticles on $\mathrm{Ti} / \mathrm{TiO}_{2}$ surfaces. Antibacterial effect on Pseudomonas aeruginosa," Journal of Colloid and Interface Science, vol. 350, no. 2, pp. 402-408, 2010.

[106] C. G. Gemmell, D. I. Edwards, A. P. Fraise et al., "Guidelines for the prophylaxis and treatment of methicillin-resistant Staphylococcus aureus (MRSA) infections in the UK," Journal of Antimicrobial Chemotherapy, vol. 57, no. 4, pp. 589-608, 2006.

[107] F. Furno, K. S. Morley, B. Wong et al., "Silver nanoparticles and polymeric medical devices: a new approach to prevention of infection?" Journal of Antimicrobial Chemotherapy, vol. 54, no. 6, pp. 1019-1024, 2004.

[108] D. J. Leaper, "Silver dressings: their role in wound management," International Wound Journal, vol. 3, no. 4, pp. 282-294, 2006.

[109] M. M. da Silva Paula, C. V. Franco, M. C. Baldin et al., "Synthesis, characterization and antibacterial activity studies of poly-styrene-acrylic acid with silver nanoparticles," Materials Science and Engineering C, vol. 29, no. 2, pp. 647-650, 2009.

[110] H. J. Jeon, J. S. Kim, T. G. Kim, J. H. Kim, W.-R. Yu, and J. H. Youk, "Preparation of poly( $\varepsilon$-caprolactone)-based polyurethane nanofibers containing silver nanoparticles," Applied Surface Science, vol. 254, no. 18, pp. 5886-5890, 2008.

[111] P.-O. Rujitanaroj, N. Pimpha, and P. Supaphol, "Wounddressing materials with antibacterial activity from electrospun gelatin fiber mats containing silver nanop articles," Polymer, vol. 49, no. 21, pp. 4723-4732, 2008.

[112] K. Madhumathi, P. T. S. Kumar, S. Abhilash et al., "Development of novel chitin/nanosilver composite scaffolds for wound dressing applications," Journal of Materials Science: Materials in Medicine, vol. 21, no. 2, pp. 807-813, 2010.

[113] S. L. Percival, P. G. Bowler, and D. Russell, "Bacterial resistance to silver in wound care," Journal of Hospital Infection, vol. 60, no. 1, pp. 1-7, 2005.

[114] P. T. S. Kumar, S. Abhilash, K. Manzoor, S. V. Nair, H. Tamura, and R. Jayakumar, "Preparation and characterization of novel $\beta$-chitin/nanosilver composite scaffolds for wound dressing applications," Carbohydrate Polymers, vol. 80, no. 3, pp. 761-767, 2010.

[115] I. Chopra, "The increasing use of silver-based products as antimicrobial agents: a useful development or a cause for concern?" Journal of Antimicrobial Chemotherapy, vol. 59, no. 4, pp. 587-590, 2007.

[116] C. Von Eiff, N. Lindner, R. A. Proctor, W. Winkelmann, and G. Peters, "Development of gentamicin-resistant Small Colony Variants of S. aureus after implantation of gentamicin chains in osteomyelitis as a possible cause of recurrence," Zeitschrift fur Orthopadie und Ihre Grenzgebiete, vol. 136, no. 3, pp. 268-271, 1998.

[117] H. Vik, K. J. Andersen, K. Julshamn, and K. Todnem, "Neuropathy caused by silver absorption from arthroplasty cement," The Lancet, vol. 1, no. 8433, p. 872, 1985.

[118] V. Alt, T. Bechert, P. Steinrücke et al., "An in vitro assessment of the antibacterial properties and cytotoxicity of nanoparticulate silver bone cement," Biomaterials, vol. 25, no. 18, pp. 4383-4391, 2004.

[119] K. Chaloupka, Y. Malam, and A. M. Seifalian, "Nanosilver as a new generation of nanoproduct in biomedical applications," Trends in Biotechnology, vol. 28, no. 11, pp. 580-588, 2010.

[120] X. Wu, J. Li, L. Wang, D. Huang, Y. Zuo, and Y. Li, "The release properties of silver ions from Ag-nHA/ $/ \mathrm{TiO}_{2} / \mathrm{PA} 66$ antimicrobial composite scaffolds," Biomedical Materials, vol. 5, no. 4, Article ID 044105, 2010.

[121] J. Ye, Q. Yao, A. Mo et al., "Effects of an antibacterial membrane on osteoblast-like cells in vitro," International Journal of Nanomedicine, vol. 6, pp. 1853-1861, 2011.

[122] J. Zhang, Q. Xu, C. Huang, A. Mo, J. Li, and Y. Zuo, "Biological properties of an anti-bacterial membrane for guided bone regeneration: an experimental study in rats," Clinical Oral Implants Research, vol. 21, no. 3, pp. 321-327, 2010.

[123] S. Saravanan, S. Nethala, S. Pattnaik, A. Tripathi, A. Moorthi, and N. Selvamurugan, "Preparation, characterization and antimicrobial activity of a bio-composite scaffold containing chitosan/nano-hydroxyapatite/nano-silver for bone tissue engineering," International Journal of Biological Macromolecules, vol. 49, no. 2, pp. 188-193, 2011.

[124] S. Sivolella, E. Stellini, G. Brunello et al., "Silver nanoparticles in alveolar bone surgery devices," Journal of Nanomaterials, vol. 2012, Article ID 975842, 12 pages, 2012. 

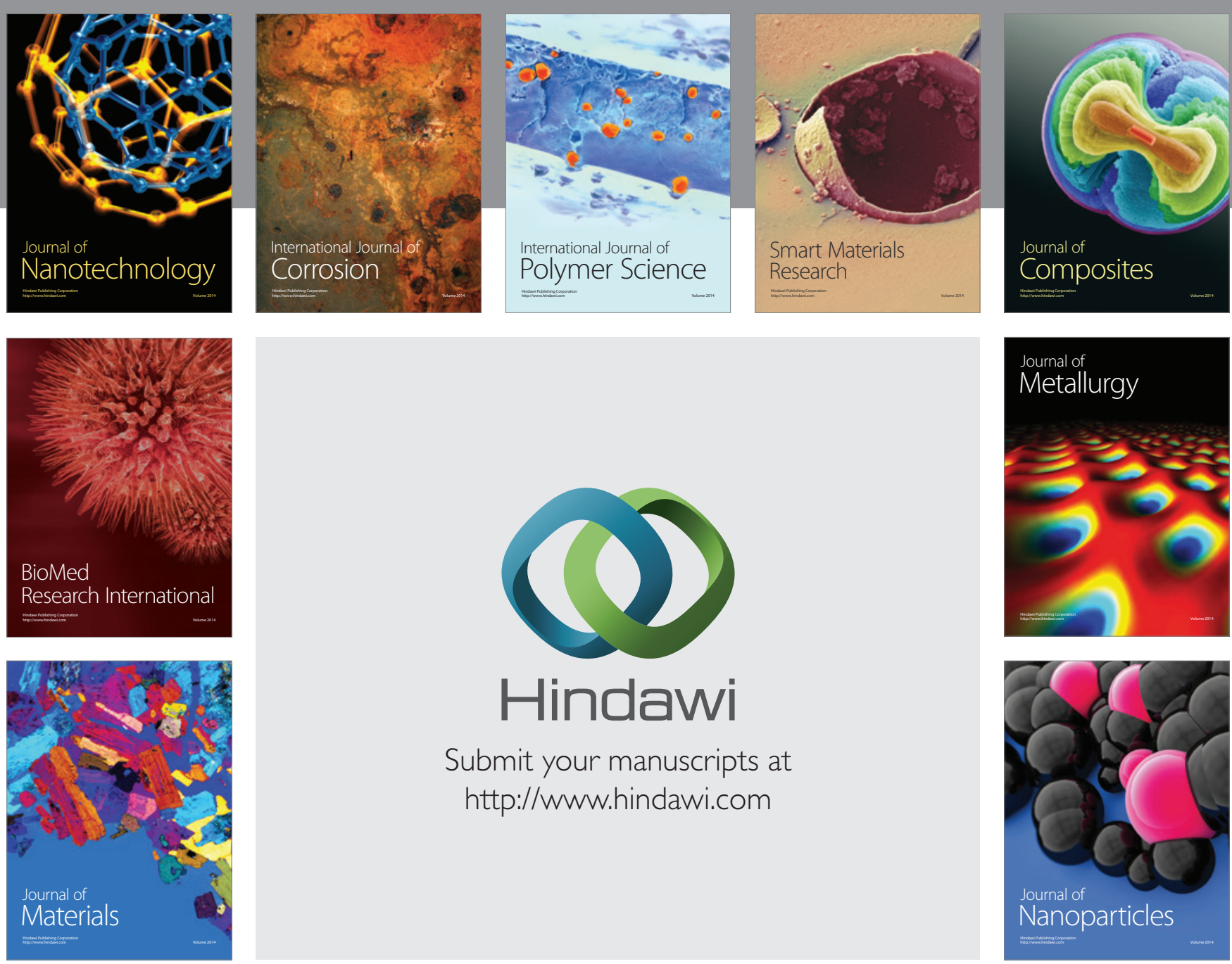

Submit your manuscripts at http://www.hindawi.com
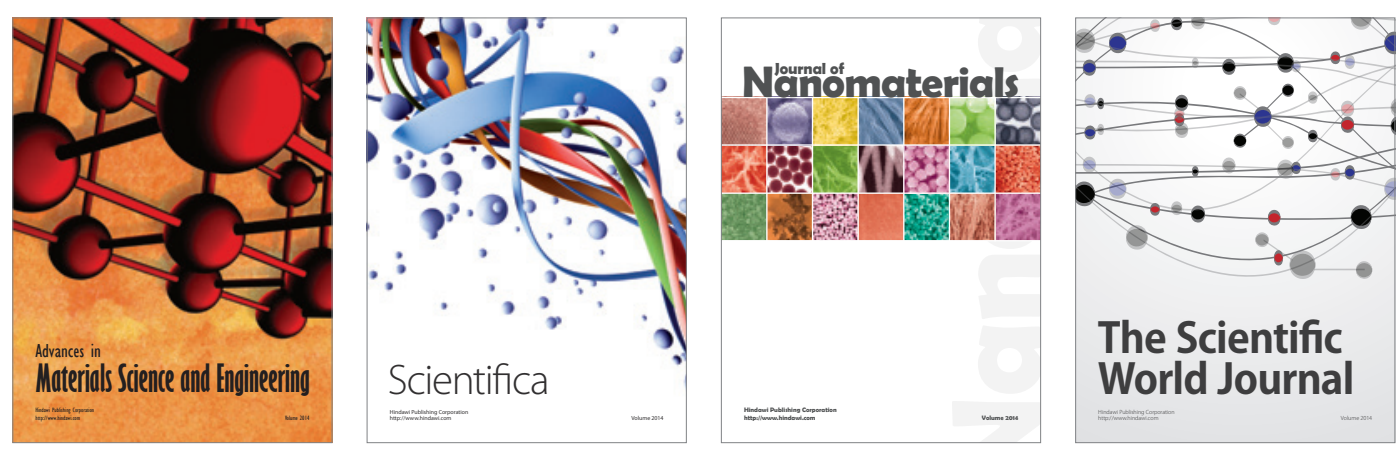

\section{The Scientific World Journal}
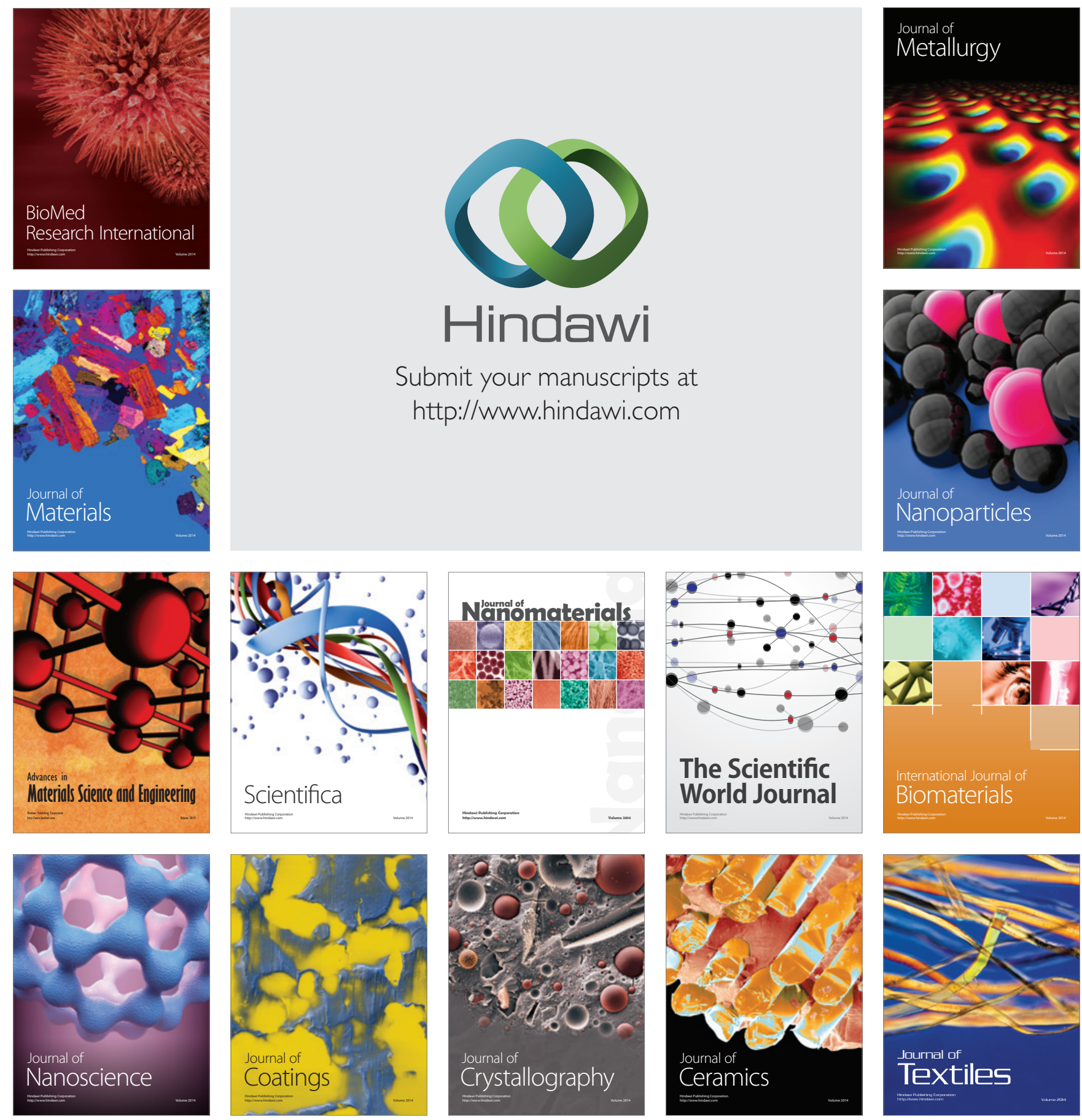